\title{
Influência da comparabilidade dos relatórios financeiros na transferência de informação em torno das externalidades dos anúncios de resultados
}

\section{Influence of the comparability of financial reports on the transfer of information around the externalities of earnings announcements}

\section{Donizete Reina}

Universidade Federal do Espírito Santo (UFES)

email:dreina2@hotmail.com

\section{Sirlei Lemes}

Universidade Federal de Uberlândia (UFU)

email:sirlemes@uol.com.br

\author{
Diane Rossi Maximiano Reina \\ Universidade Federal do Espírito Santo (UFES/ES) \\ email:dianereina@hotmail.com
}

\section{RESUMO}

O objetivo desta pesquisa foi avaliar a influência da comparabilidade dos relatórios financeiros na transferência de informação, considerando os efeitos das externalidades em torno dos anúncios de resultados das empresas. A comparabilidade foi mensurada com o modelo de similaridades das funções contábeis; a transferência de informação foi mensurada com a técnica de estudo de evento e testada com análise de regressão com dados em painel, no período de 2012 a 2018, em 122 companhias brasileiras. Os resultados são: (i) a comparabilidade pode influenciar a reação do mercado em torno do volume anormal de negociação, sugerindo que os anúncios de resultados das companhias geram externalidades das informações; (ii) o efeito da comparabilidade na transferência de informação não depende totalmente da quantidade de analistas que acompanham as empresas; e (iii) a transferência de informação e a comparabilidade estão associados à reação do mercado quando são auditados pela mesma firma de auditoria. Assim, pode-se concluir que a comparabilidade dos relatórios financeiros funciona como um previsor de monitoramento dos padrões de informações divulgadas, em função da capacidade de minimizar os efeitos negativos das externalidades dessas informações.

Palavras-Chave: Comparabilidade. Relatórios Financeiros. Transferência de Informação. Anúncio de Resultados. Externalidade das Informações.

\section{ABSTRACT}

The objective of this research was to evaluate the influence of the comparability of financial reports on the transfer of information, considering the effects of externalities around companies earnings announcements. Comparability was measured using the accounting function similarity model; the transfer of information was measured using the event study technique and tested with regression analysis with panel data, from 2012 to 2018, in 122 Brazilian companies. The results are: (i) comparability may influence market reaction to abnormal trading volume, suggesting that companies' earnings announcements generate information externalities; (ii) the effect of comparability on the transfer of information does not depend entirely on the number of analysts who monitor the companies; and (iii) the transfer of information and comparability are associated with the reaction of the market when they are audited by the same audit firm. Thus, it can be concluded that the comparability of financial reports works as a predictor for monitoring the patterns of information disclosed, due to the ability to minimize the negative effects of externalities of this information.

Key-words: Comparability. Financial Reports. Information Transfer. Results Announcement. Externality of Information. 


\section{INTRODUCTION}

A reação do mercado de capitais ao conteúdo informacional dos resultados anunciados pela primeira empresa no setor econômico tende a ser maior ao anúncio dos resultados das empresas que divulgam após a primeira (FOSTER, 1981). Isso ocorre porque as informações fornecidas pelos primeiros anunciantes podem ser usadas para prever as notícias das empresas que anunciam seus resultados posteriormente (FREEMAN; TSE, 1992). A ideia subjacente a isso é que a empresa do setor, que primeiro anunciar seus resultados, transfere informações a partir de sua divulgação ao mercado de capitais, as quais antes não estavam disponíveis, mas que agora auxiliam na avaliação das demais companhias do setor que ainda não haviam anunciado seus resultados.

As externalidades da informação nos mercados de capitais ocorrem quando a divulgação de informações de uma empresa afeta a avaliação das ações de outra empresa. Intuitivamente, as externalidades da informação são mais prováveis de ocorrer entre empresas economicamente relacionadas, como companhias do mesmo setor (PANDIT; WASLEY; $\mathrm{ZACH}, 2011$ ). Ainda segundo os mesmos autores, estudos anteriores têm se dedicado a documentar resultados sobre as externalidades das informações intrasetoriais (às vezes, chamadas de "transferências de informações") por ocasião de eventos, como anúncios de lucros e de previsões de resultados da gestão, realizados por empresas do mesmo setor econômico.

As empresas do mesmo setor econômico têm propriedades operacionais semelhantes e enfrentam choques econômicos semelhantes. Empresas em diferentes setores podem ter propriedades operacionais diferentes e enfrentar choques específicos do setor (YIP; YOUNG, 2012). Dessa forma, como uma expressão das externalidades das informações, a transferência de informações entre empresas evidencia que as informações de uma empresa são valiosas para atualizar expectativas ou verificar informações sobre outra empresa (FOSTER, 1981; WEICHAO; DAOGUANG; SIYI, 2018; ROYCHOWDHURY; SHROFF; VERDI, 2019).

O impacto da comparabilidade na transferência de informações pode ser analisado tendo os anúncios de resultados como fonte de informações, já que as informações sobre os resultados das companhias são a saída mais importante do sistema contábil e desempenham valioso papel nas tomadas de decisão dos investidores. Ademais, mesmo que as informações dos resultados das empresas que não anunciam sejam conhecidas, os investidores ainda possuem algum incentivo para usar informações de empresas semelhantes (WEICHAO; DAOGUANG; SIYI, 2018).

O tamanho da empresa e o tempo de divulgação podem afetar o conteúdo das informações divulgadas nos anúncios dos resultados anuais, assim como um conteúdo de informações precárias pode não resultar em transferência de informações. Desse modo, quando uma empresa divulga informações sobre seus resultados, todas as outras empresas do mesmo setor provavelmente reagirão a essa divulgação. Não existem, porém, pesquisas suficientes para mostrar que empresas menores ou empresas com divulgação tardia não possam incorrer em transferência de informação (WEICHAO; DAOGUANG; SIYI, 2018).

A imitação de políticas na divulgação de conteúdo informacional ocorre porque os gestores procuram ganhar legitimidade e credibilidade para justificar suas decisões, com base em políticas de outras empresas maiores do setor econômico, com objetivo de se defenderem contra possíveis questionamentos em ambientes incertos (FRANCO; HOU; MA, 2019). Além disso, segundo Franco, Hou e Ma (2019), as empresas tendem a imitar as políticas de outras empresas no setor econômico, especialmente as de outras maiores e mais estabelecidas dentre os setores, considerados mais bem-sucedidos.

Pelo exposto até aqui, busca-se, preencher uma lacuna de pesquisa relacionada a associação entre a comparabilidade dos relatórios financeiros e a transferência de informação, considerando os efeitos das externalidades das informações em torno dos anúncios de resultados em companhias brasileiras. Para isso, neste estudo, analisou-se a influência da comparabilidade dos relatórios financeiros na transferência de informação, considerando os efeitos das externalidades em torno dos anúncios de resultados das empresas.

A motivação para avaliar a associação entre a comparabilidade do relatório financeiro, a transferência de informação e a externalidade dos anúncios de resultados está vinculada à perspectiva de que 
a comparabilidade dos relatórios financeiros pode aumentar a transferência de informações, em um ambiente econômico semelhante, entre as empresas (QINGYUAN; LUMENG, 2018). Nesse contexto, a pesquisa presente contribui com evidências práticas envolvendo a reação do mercado brasileiro aos anúncios de resultados das empresas por meio do volume anormal de negociação. Ademais, esta pesquisa destaca-se por ampliar a compreensão do papel da comparabilidade dos relatórios financeiros na transferência de informação, em função de que a comparabilidade pode minimizar os efeitos negativos das externalidades das informações em torno dos anúncios de resultados.

Por fim, os resultados desta pesquisa, também podem impactar as premissas adotadas na teoria da divulgação, uma vez que as pesquisas envolvendo a perspectiva de associação entre as variáveis buscam explicar o fenômeno da divulgação de informações financeiras e seus efeitos nos preços das ações e no comportamento dos investidores, os quais competem no ambiente de mercado de capitais, como agentes que procuram maximizar seus retornos, incorporando a divulgação dos anúncios das companhias às suas crenças, de maneiras diversas. Nesse sentido, cabe destacar a importância das pesquisas sobre a comparabilidade dos relatórios financeiros com foco no resultado das empresas, que são as saídas mais importantes do sistema contábil de uma empresa e desempenham papel essencial na tomada de decisões dos investidores.

\section{REFERENCIAL TEÓRICO}

De acordo com Foster (1981) e Baginski (1987), quando a informação divulgada pela empresa i gera uma revisão inesperada do preço da ação para a empresa j, ocorre uma transferência de informação. Nesse sentido, se as transferências de informações implícitas pelas divulgações antecipadas do anunciante forem, adequadamente, incorporadas aos preços das ações dos anunciantes atrasados, não deverá haver movimentos previsíveis nos preços quando esses anunciantes atrasados informarem, posteriormente, seus resultados (THOMAS; ZHANG, 2008).
A empresa i (definida como empresa anunciadora) divulga as informações sobre seus resultados em no período t1, e essa divulgação afeta o volume anormal de negociação das empresas do mesmo setor, representadas pela empresa $\mathrm{j}$ (definida como empresa não anunciadora), que reagem à divulgação da empresa i. As reações dos volumes anormais de negociação da empresa $\mathrm{j}$ ao anúncio de resultados da empresa i capturam a demanda de informações externas dos investidores da empresa $\mathrm{j}$ (WEICHAO; DAOGUANG; SIYI, 2018). Esse processo demonstra que as informações são transferidas da empresa i, quando de seus anúncios de resultados, para a empresa $\mathrm{j}$, e que essas informações são utilizadas pelos investidores do mercado de capitais em suas decisões nas empresas j, dado que as empresas i e j pertencem ao mesmo setor econômico.

As informações comparáveis de empresas do mesmo setor econômico podem, de várias maneiras, melhorar a eficiência de investimento de uma empresa. Dentre essas várias maneiras, uma é que essas informações podem ajudar os gestores a tomar melhores decisões de investimento; e outra é que informações comparáveis de empresas do mesmo setor econômico permitem que os investidores avaliem e monitorem, efetivamente, os projetos de investimento das empresas (CHEN; YOUNG; ZHUANG, 2013). Além disso, para os mesmos autores, semelhante aos gestores, os investidores podem usar as informações relatadas pelas empresas pares para atenuar suas incertezas sobre as condições do mercado de capitais e distinguir entre os melhores e os piores projetos de investimento.

A comparabilidade dos relatórios financeiros se destaca como um significativo determinante da utilidade da informação financeira ao transferir informações confiáveis entre empresas anunciantes e não anunciantes do mesmo setor econômico, dado que, quando uma empresa anunciante divulga informações de seus resultados, todas as outras empresas do setor econômico provavelmente reagirão a essa divulgação (WEICHAO; DAOGUANG; SIYI, 2018). As pesquisas sugerem que empresas pertencentes a um setor econômico têm mais acesso às informações se comparadas com investidores independentes, devido à frequência e natureza das suas interações 
Quadro 1 Síntese dos Estudos Assemelhados

\begin{tabular}{|c|c|c|}
\hline Autor (es) & Objetivos & Resultados \\
\hline $\begin{array}{l}\text { Franco, Kothari e Verdi } \\
\text { (2011) }\end{array}$ & $\begin{array}{l}\text { Desenvolveram uma medida de mensu- } \\
\text { ração da comparabilidade das demons- } \\
\text { trações financeiras com base no lucro e } \\
\text { nos eventos econômicos relacionados. }\end{array}$ & $\begin{array}{l}\text { A medida está positivamente relacionada com a precisão de acompa- } \\
\text { nhamento e com a previsão dos analistas, sugerindo que a compara- } \\
\text { bilidade das demonstrações contábeis reduz o custo de aquisição de } \\
\text { informações e aumenta a qualidade geral das informações, disponíveis } \\
\text { aos analistas. }\end{array}$ \\
\hline $\begin{array}{l}\text { Alves, Pope e Young } \\
\text { (2011) }\end{array}$ & $\begin{array}{l}\text { Testaram se a existência e magnitude } \\
\text { de transferência de informações estão } \\
\text { associadas ao anúncio dos resultados } \\
\text { das companhias entre países da união } \\
\text { europeia. }\end{array}$ & $\begin{array}{l}\text { As surpresas negativas dos anúncios divulgadas pelas empresas em um } \\
\text { país afetam a percepção dos investidores de empresas comparáveis } \\
\text { que não anunciam em outros países. Ademais, a forma e a magnitude } \\
\text { dos efeitos entre países são consistentes com as transferências de } \\
\text { informações internas dos países e os efeitos variam de acordo com as } \\
\text { características das empresas, setor econômico e dos países. }\end{array}$ \\
\hline $\begin{array}{l}\text { Chen, Young e Zhuang } \\
\text { (2013) }\end{array}$ & $\begin{array}{l}\text { Testaram os efeitos das externalidades } \\
\text { após adoção das IFRS, analisando os } \\
\text { retornos sobre os ativos. }\end{array}$ & $\begin{array}{l}\text { Os efeitos de transbordamento são significativamente afetados pela } \\
\text { força da aplicação da lei (enforcement), composição das firmas pares e } \\
\text { ambientes de concorrência do setor e que o aumento da divulgação } \\
\text { tanto por empresas estrangeiras quanto por empresas nacionais do } \\
\text { mesmo setor econômico após a adoção das IFRS afeta a eficiência dos } \\
\text { investimentos de uma empresa. Além disso, evidenciaram que existe } \\
\text { externalidades positivas da regulamentação das IFRS sobre a eficiência } \\
\text { do investimento das empresas. }\end{array}$ \\
\hline Wang (2014) & $\begin{array}{l}\text { Verificou se a harmonização dos padrões } \\
\text { contábeis aumenta a comparabilidade } \\
\text { das informações financeiras entre países } \\
\text { europeus. }\end{array}$ & $\begin{array}{l}\text { A harmonização dos padrões contábeis facilita a transferência de } \\
\text { informações transnacionais; e sugerem a comparabilidade como um } \\
\text { mecanismo direto para isso. Além disso, o estudo evidenciou que } \\
\text { empresas experimentam um aumento significativo nas reações do } \\
\text { mercado quanto à liberação de lucros por adotantes voluntários, após a } \\
\text { adoção obrigatória. }\end{array}$ \\
\hline $\begin{array}{l}\text { Habib, Hasan e Al-Hadi } \\
\text { (2017) }\end{array}$ & $\begin{array}{l}\text { Verificaram os efeitos da comparabilida- } \\
\text { de das demonstrações financeiras nas } \\
\text { disponibilidades de caixa, em empresas } \\
\text { americanas. }\end{array}$ & $\begin{array}{l}\text { Maior grau de comparabilidade reduz os custos de aquisição de } \\
\text { informações e as incertezas associados à avaliação de desempenho; e } \\
\text { aumenta a quantidade e a qualidade geral de informação disponível a } \\
\text { empresas externas. Além disso, existe evidências consistentes de que a } \\
\text { comparabilidade das demonstrações contábeis reduz, significativamen- } \\
\text { te, o caixa da empresa. }\end{array}$ \\
\hline $\begin{array}{l}\text { Byard, Mashruwala e } \\
\text { Suh (2017) }\end{array}$ & $\begin{array}{l}\text { Verificaram se a mudança na regra da } \\
\text { SEC reduziu a comparabilidade perce- } \\
\text { bida pelos investidores nos relatórios } \\
\text { financeiros. }\end{array}$ & $\begin{array}{l}\text { Os resultados mostraram que, com a mudança de regra, houve uma } \\
\text { diminuição na comparabilidade para analistas financeiros que preveem } \\
\text { lucros para empresas comparáveis. }\end{array}$ \\
\hline $\begin{array}{l}\text { Weichao, Daoguang e } \\
\text { Siyi (2018) }\end{array}$ & $\begin{array}{l}\text { Verificaram o impacto da comparabilida- } \\
\text { de das informações contábeis na transfe- } \\
\text { rência de informações no mercado de } \\
\text { capitais da China. }\end{array}$ & $\begin{array}{l}\text { Os aumentos na comparabilidade dos relatórios financeiros podem } \\
\text { facilitar a transferência de informações de ganhos entre as empresas, } \\
\text { independentemente de o investidor usar as informações para esperar } \\
\text { informações desconhecidas ou verificar as informações existentes, e } \\
\text { que o uso de informações comparáveis pelos investidores reduz a res- } \\
\text { posta do mercado às informações quanto aos ganhos das empresas. }\end{array}$ \\
\hline $\begin{array}{l}\text { Franco, Hou e Ma } \\
\text { (2019) }\end{array}$ & $\begin{array}{l}\text { Investigaram como a localização da sede } \\
\text { das empresas afeta a comparabilidade } \\
\text { das demonstrações financeiras das em- } \\
\text { presas entre setores econômicos. }\end{array}$ & $\begin{array}{l}\text { A comparabilidade dos relatórios financeiros entre uma empresa líder } \\
\text { de setor e uma empresa imitadora de suas divulgações é maior do que } \\
\text { entre duas empresas que tendem a imitar a empresa líder do setor. As } \\
\text { empresas pares que estão atuando na mesma região possuem maior } \\
\text { comparabilidade nos relatórios financeiros do que as empresas que } \\
\text { pertencem ao mesmo setor econômico, porém estão localizadas em } \\
\text { regiões diferentes. }\end{array}$ \\
\hline Henry et al. (2020) & $\begin{array}{l}\text { Analisaram o efeito da comparabilidade } \\
\text { na cobertura dos analistas, na precisão } \\
\text { da previsão e na dispersão da previsão. }\end{array}$ & $\begin{array}{l}\text { A comparabilidade das demonstrações financeiras se relaciona entre } \\
\text { lucros e atributos de previsão dos analistas, e os efeitos da compara- } \\
\text { bilidade dos lucros ocorrem direta e indiretamente. O aumento da } \\
\text { comparabilidade aumenta a cobertura do analista, melhora a precisão } \\
\text { das previsões dos analistas e reduz a prevenção da dispersão. }\end{array}$ \\
\hline
\end{tabular}

Fonte: Elaborado pelos autores 
com as outras empresas do mesmo setor econômico (ROYCHOWDHURY; SHROFF; VERDI, 2019).

Pesquisas anteriores mostram que tanto a convergência contábil como a qualidade da informação são prováveis direcionadores da melhoria da comparabilidade, quando analisados pela associação entre a surpresa do lucro de uma empresa anunciante e os movimentos contemporâneos do preço das ações de outras empresas (YIP; YOUNG, 2012), e que a harmonização dos padrões contábeis facilita a transferência de informações entre países, sugerindo a comparabilidade como um mecanismo direto para isso (WANG, 2014). Entretanto, de acordo com Gross e Perotti (2017), as pesquisas sobre comparabilidade dos relatórios financeiros seguem na perspectiva dos resultados dos relatórios financeiros, principalmente dos resultados das companhias. Nesse sentido, no Quadro 1, constituído pela síntese dos estudos, percebe-se, que o foco das pesquisas está concentrado nos resultados dos eventos econômicos relacionados à comparabilidade.

$\mathrm{Na}$ esteira dos estudos apresentados no Quadro 1 , entende-se que, no contexto do anúncio de resultados de empresas anunciadoras e não anunciadoras, uma externalidade da informação divulgada ocorre quando uma empresa, que anuncia posteriormente, exibe uma reação no volume anormal de negociação diferente de zero ao evento de divulgação da empresa, que anuncia primeiro seus resultados (FOSTER, 1981; FIRTH, 1996; THOMAS; ZHANG, 2008; PANDIT; WASLEY; ZACH, 2011). De acordo com a literatura, a ideia subjacente para esperar esse efeito é que a empresa do setor econômico que primeiro anunciar seus resultados transfere ao mercado de capitais, a partir de sua divulgação, informações que antes não estavam disponíveis, mas que agora auxiliam na avaliação das demais companhias do setor que ainda não anunciaram seus resultados (FOSTER, 1981; FREEMAN; TSE, 1992; FIRTH, 1996; THOMAS; ZHANG, 2008; PANDIT; WASLEY; ZACH, 2011).

Para De Franco, Kothari e Verdi (2011), uma maior comparabilidade dos resultados aumenta o acompanhamento dos analistas, melhora a precisão das previsões e diminui a dispersão prevista dos analistas (FRANCO; KOTHARI; VERDI, 2011). Nesse raciocínio, medidas de comparabilidade relacionadas a preços capturam a comparabilidade das perspectivas de investidores e analistas, pois, juntos, provavelmente, são os maiores grupos que usam informações contábeis divulgadas, sendo que, para tomar decisões de investimento, é importante examinar a comparabilidade a partir de suas perspectivas (YIP; YOUNG, 2012). Diante do exposto, formula-se a seguinte hipótese:

$H_{1:} O$ aumento do volume anormal de negociação em torno dos anúncios de resultados, experimentado por uma empresa que possui maior cobertura de analistas de mercado, está associado, positivamente, ao aumento da comparabilidade de seus relatórios financeiros.

O entendimento do analista em relação à empresa anunciadora afeta não apenas a eficiência da transferência de informações dentro do setor, mas também a capacidade do analista de interpretar as informações divulgadas na previsão. Assim, ao disseminar informações que facilitam aos analistas preverem os resultados da empresa divulgadora, empresas que mantêm padrões de divulgação de alta qualidade e/ou emitem previsões de gerenciamento também fornecem informações que beneficiam analistas que seguem outras empresas, no mesmo setor econômico (HILARY; SHEN, 2013). Além disso, os mesmos autores ainda reforçam que, os analistas ajudam o mercado de capitais a aplicar informações de uma empresa a outra, e a experiência desses analistas tem um efeito positivo sobre a eficiência dessa transferência de informações.

A comparabilidade está associada a um maior volume de investimentos estrangeiros (FOND et al., 2011; FANG; MAFFETT; ZHANG, 2015). Nesse sentido, mudanças nas normas podem alterar a percepção, tanto dos investidores quanto dos analistas, em relação à transferência de informações, considerando que tal mudança pode aumentar a incerteza do investidor em relação ao grau de informações transferidas, já que, com a mudança, o investidor precisará atualizar suas crenças referentes às informações de uma empresa, que são anunciadas publicamente em relação às empresas que anunciam posteriormente, mesmo sendo comparáveis em níveis setoriais (BYARD; MASHRUWALA; SUH, 2017).

Segundo Byard et al. (2018), os analistas tendem a seguir (dar cobertura), seletivamente, as empresas 
que eles esperam que se saiam bem no futuro, transmitindo informações mais úteis para empresas com perdas do que para empresas lucrativas. Nessa perspectiva, níveis anormais de cobertura dos analistas podem ser um forte preditor de desempenho futuro das empresas lucrativas ou não, dado que os analistas possuem critérios sobre a quais empresas dar cobertura e têm capacidade de escolher as empresas com melhor futuro (BYARD et al., 2018).

O efeito da comparabilidade pode afetar a precisão de previsão dos analistas, e o aumento da comparabilidade aumenta a cobertura dos analistas, melhora a precisão das previsões destes e reduz a prevenção da dispersão, tanto direta como indiretamente, formando, os analistas de ações, um grupo importante de usuários das demonstrações contábeis (HENRY et al., 2020). Nesse sentido, para prever as perspectivas futuras das empresas, uma cobertura maior de analistas é útil e está mais associada ao desempenho futuro, como retorno das ações e dos ativos, para empresas que divulgam perdas do que para empresas que divulgam lucros (BYARD et al., 2018).

Para Oliveira et al. (2018, p. 27), "o ponto central do trabalho dos analistas do mercado de capitais é analisar a situação econômico-financeira atual e prospectiva das empresas". Assim, se a comparabilidade subjacente entre os processos contábeis de duas empresas mudar, a mudança será refletida na estrutura das demonstrações financeiras, por meio das quais os resultados contábeis são comunicados, e essa mudança afetará tanto os analistas, quanto as informações transferidas na percepção desses analistas (HENRY et al., 2020).

Como as companhias comparáveis constituem boas referências entre si, a transferência de informações entre elas poderia reduzir a quantidade de esforços exercidos pelos analistas na compreensão e análise de suas demonstrações financeiras (KIM et al., 2016). O benefício da comparabilidade, no entanto, não se restringe ao campo dos analistas, das empresas, dos gestores e investidores, dado que as partes que regulam a contabilidade também podem perceber uma forma de melhorar a comparabilidade para atender mais usuários e aumentar ainda mais a qualidade dos relatórios financeiros (FRANCO; HOU; MA, 2019). Dessa forma, em vista das consequências econômicas da comparabilidade das demonstrações financeiras, torna-se relevante o conhecimento de seus determinantes para as partes interessadas, que usam e regulam esses relatórios financeiros (FRANCO; HOU; MA, 2019).

A divulgação das empresas auditadas pela mesma empresa de auditoria que as demais empresas do setor econômico pode influenciar a transferência de informação em torno dos anúncios de resultados, já que as recomendações das empresas de auditoria podem seguir um padrão, em função de as empresas pertencerem a um mesmo setor de atividade econômica. Essa variável indica que as empresas que partilham as mesmas empresas de auditoria tendem a ser mais comparáveis (FRANCIS; PINNUCK; WATANABE, 2014). Tal perspectiva também foi corroborada na pesquisa de Franco, Hou e Ma (2019).

O estilo de auditoria implica que duas empresas auditadas pela mesma empresa de auditoria estão sujeitas ao mesmo estilo de auditoria, tendo, dessa forma, maior probabilidade de que seus resultados anunciados sejam mais comparáveis do que quando duas empresas são auditadas por empresas diferentes de auditoria, dado que as empresas de auditoria possuem estilos diferentes.

Além de um único conjunto de normas ser um meio de aumentar a comparabilidade, o trabalho do auditor, como agente econômico, também é importante para proporcionar melhor comparabilidade em termos contábeis (FRANCIS; PINNUCK; WATANABE, 2014). O argumento para essa perspectiva é que cada empresa de auditoria possui um estilo ou tem seu próprio conjunto de regras internas, com relação à interpretação e implementação de determinadas normas de auditorias e normas de contabilidade. Além disso, cada setor econômico é composto por atividades econômicas, com certas similaridades. Assim, quando uma empresa de auditoria audita mais de uma empresa no setor econômico, existe a possibilidade de que essas informações possam ser mais comparáveis, em função do estilo e regramentos da própria empresa que faz a auditoria (FRANCIS; PINNUCK; WATANABE, 2014).

Por fim, destaca-se que, quando uma empresa do setor possui empresa de auditoria semelhante às demais, espera-se que essa característica também interfira no volume anormal de negociação em torno dos anúncios dos resultados, dado que as empresas 
concorrentes podem utilizar as informações comparáveis das empresas pares para tomar suas decisões (FRANCO; HOU; MA, 2019). Nessa perspectiva formula-se a seguinte hipótese:

$\mathrm{H}_{2:} \mathrm{O}$ aumento do volume anormal de negociação em torno dos anúncios de resultados, experimentado por uma empresa quando compartilha a mesma empresa de auditoria com as demais empresas do setor econômico, está associado, positivamente, ao aumento da comparabilidade de seus relatórios financeiros.

Para testar as hipóteses acima, adota-se, como forma de medir a transferência de informação, o volume anormal de negociação das companhias, em função do tempo de divulgação dos resultados de uma empresa em relação às datas de divulgação das outras companhias. Assim, foram consideradas, neste estudo, como empresas anunciadoras (EA) a primeira empresa que divulga seus resultados. As demais empresas foram consideradas como empresas que anunciam posteriormente (ou empresas não anunciadoras - ENA). Han e Wild (1990), Thomas e Zhang (2008) e Weichao, Daoguang e Siyi (2018), em seus estudos, fazem separação similar.

\section{PROCEDIMENTOS METODOLÓGICOS}

A classificação dos setores foi feita com base no padrão internacional North American Classification System - NAICS (nível 2), que aumentou a quantidade de companhias disponíveis para o estudo no contexto brasileiro (RIBEIRO et al., 2016). Esta pesquisa foi delimitada pelo período de 2012 a 2018, com estimação contábil dos dados entre os anos de 2008 e 2011. A escolha desse recorte teve como objetivo dissipar os eventuais choques causados aos retornos das companhias brasileiras por eventos extraordinários, como a Crise Financeira de 2008 e 2009, maior utilização de accruals discricionários (RIBEIRO et al., 2016), e o nível de utilização de accruals discricionários foi maior no período da adoção inicial das IFRS, especialmente nos anos de 2007 a 2010, diminuindo apenas no ano de 2011 (SILVA, 2013).
Os dados sobre lucro líquido, datas dos anúncios dos resultados das companhias, ativo total, empresas de auditoria, quantidade de analistas que acompanham as empresas, retornos sobre as ações, volume de ações negociadas, valor de mercado das empresas, assim como os dados das variáveis de controle foram coletados nos site da $[\mathrm{B}]^{3}$ Brasil, Bolsa, Balcão, site das companhias e site da Comissão de Valores Mobiliário (CVM), na base de dados Economatica ${ }^{\oplus}$ na base de dados da Thomson One Analytics Refinitiv ${ }^{\oplus}$.

O retorno sobre as ações foi obtido com base nas ações ordinárias e, na falta destas, foram referidas as ações preferenciais. Destaca-se que, uma vez definido o tipo de ação (ordinária ou preferencial) como base não houve alteração do tipo de ação no decorrer dos anos. Esse procedimento foi adotado para evitar distorções na comparabilidade dos relatórios financeiros em função de o volume de negociação entre as ações preferenciais e ordinárias oscilar no decorrer dos anos. A comparabilidade dos relatórios financeiros foi mensurada conforme o modelo de Franco, Kothari e Verdi (2011). Os dados para calcular o volume anormal de negociação foram obtidos por meio da técnica de estudo de eventos, a partir das datas dos anúncios de resultados das companhias.

Inicialmente, foram identificadas $441 \mathrm{com}$ panhias na $[B]^{3}$, em 21/10/2018. Desse total, foram excluídas: companhias que não divulgaram nenhum valor de ativo e/ou não havia dados disponíveis para o período (183); companhias do setor bancário/financeiro por seguir regulamentação própria, divulgando em IFRS apenas as demonstrações consolidadas (63); companhias do setor de gestão de companhias e empreendimentos (holdings e participações em outras empresas) (25); e companhias pertencentes a 17 setores econômicos com menos de cinco empresas no setor (48).

Outros critérios adotados para exclusões foram: (i) encerramento do exercício fiscal das empresas em 31 de dezembro; (ii) datas de arquivamento dos anúncios de resultados disponíveis no site da CVM como forma de diferenciar as empresas anunciadoras e não anunciadoras; (iii) as datas consideradas para divulgação dos anúncios foram as primeiras divulgações realizadas pelas empresas; e, foram excluídos os setores com menos de cinco empresas como forma de minimizar os possíveis efeitos cruzados da divulgação 
e os efeitos de contágio (WEICHAO; DAOGUANG; SIYI, 2018; THOMAS; ZHANG, 2008). Assim, após as devidas exclusões, foram selecionadas 122 empresas-ano referente ao período de 2012 a 2018, total-

Tabela 1 Composição da Amostra izando 854 observações, distribuídas em 12 setores, conforme exposto na Tabela 1. No Apêndice 1 está disponível a lista completa das companhias e suas respectivas datas de anúncio de resultados.

\begin{tabular}{c|l|c|c|c}
\hline SETOR & \multicolumn{1}{|c|}{ SETOR ECONÔMICO } & EMPRESAS & OBS. EMP.-ANO & \% \\
\hline 1 & Produção agrícola & 5 & 35 & $4,10 \%$ \\
\hline 2 & Serviços de utilidade pública (eletricidade, gás e água) & 33 & 231 & $27,05 \%$ \\
\hline 3 & Construção de edifícios & 12 & 84 & $9,84 \%$ \\
\hline 4 & Indústria de alimentos & 8 & 56 & $6,56 \%$ \\
\hline 5 & Indústria têxtil & 7 & 49 & $5,74 \%$ \\
\hline 6 & Indústria química & 9 & 63 & $7,38 \%$ \\
\hline 7 & Indústria de metal primário & 9 & 63 & $7,38 \%$ \\
\hline 8 & Indústria de produtos de metal & 5 & 35 & $4,10 \%$ \\
\hline 9 & Indústria de máquinas & 6 & $4,92 \%$ \\
\hline 10 & Fábrica de equipamentos de transporte & 10 & 70 & $8,20 \%$ \\
\hline 11 & Telecomunicações & 6 & $\mathbf{7 2}$ & $4,92 \%$ \\
\hline 12 & Imobiliário & $\mathbf{1 2 2}$ & 84 & $\mathbf{8 5 4}$ \\
\hline
\end{tabular}

Fonte: Elaborada pelos autores

Os documentos considerados como veículos para os anúncios dos resultados divulgados e arquivados pelas companhias na CVM são: a) demonstrações financeiras anuais completas; b) relatório anual da administração; c) press-release; d) comunicado ao mercado; e) apresentação de resultados aos analistas e agentes de mercado; f) demonstrações financeiras em padrões internacionais; g) demonstrações financeiras intermediárias e resultados trimestrais; e h) aviso aos acionistas. Desse modo, seguindo o estudo de Weichao, Daoguang e Siyi (2018), que adotou as datas de divulgação da Comissão de Valores Mobiliários da China como referência de data de anúncio dos resultados das companhias, considerou-se, como data de divulgação dos resultados (ou data de anúncio dos resultados), as datas de arquivamento das companhias na CVM.

Os dados foram analisados utilizando-se modelos de regressão para dados em painel balanceado (GUJARATI; PORTER, 2011; FÁVERO et al., 2014), com três abordagens para estimação dos modelos de regressão, a saber: i) Pooled (POLS) - efeito combinado, (ii) EA - efeito aleatório; e (iii) EF - efeitos fixos. Além disso, foi adotado os seguintes procedimentos: 1) verificação de homogeneidade [pelo Teste Breusch-Pagan $\left(\chi^{2}\right)$ ], especificação [pelo Teste RESET de Ramsey $(F)$ ] e multicolinearidade [pelo exame do fator de inflação da variância (FIV)]; e, 2) realização do Teste LM de Breusch-Pagan para definir entre os modelos POLS, efeitos aleatórios, do Teste de Hausman para escolher entre os modelos efeitos aleatórios, efeitos fixos, e realização do Teste de Chow (Teste LM de restrição de modelos) para decidir entre os modelos Pooled (POLS) e efeitos fixos.

\subsection{Mensuração da comparabilidade dos relatórios financeiros}

Para o cálculo da medida de comparabilidade, foram selecionados os tipos de ação (ordinária ou preferencial), que apresentaram a maior presença diária média de negociação em pregão, no período 
analisado. Depois dessa primeira seleção, para evitar o efeito no retorno, foi mantida a opção de ação escolhida inicialmente, pois os preços das ações preferenciais e ordinárias podem ser diferentes e provocar distorções na medida de comparabilidade (FRANCO; KOTHARI; VERDI, 2011; RIBEIRO et al., 2016).

$\mathrm{Na}$ aplicação do modelo proposto por Franco, Kothari e Verdi (2011), três adaptações foram feitas para o contexto brasileiro: 1) adoção do lucro líquido no lugar de lucro operacional, visto que a figura do lucro operacional deixou de existir a partir da adoção das IFRS no Brasil. Essa adaptação também foi realizada por Ribeiro et al. (2016) e Reina et al. (2019); 2) no modelo original de Franco, Kothari e Verdi (2011), a estimação contábil foi feita com base em informações trimestrais das empresas. Entretanto, a estimação da função contábil individual foi feita com dados anuais, em razão da dificuldade de identificar os dados trimestrais das empresas no contexto brasileiro; e, 3) como deflator do lucro líquido, empregou-se o ativo total final em vez do valor de mercado da companhia, usado no modelo original. Adicionalmente, destaca-se que o único objetivo de deflacionar o lucro é retirar qualquer efeito resultante do tamanho do modelo (RIBEIRO et al., 2016) e, como a comparabilidade é uma medida relativa, o importante é adotar a mesma medida para todas as empresas (RIBEIRO et al., 2016).

Para o cálculo da comparabilidade média das empresas, foram selecionados os tipos de ação (ordinária ou preferencial), que apresentaram maior presença diária em pregão, no período do estudo. Para mensurar a medida de comparabilidade, estimou-se a função contábil individual de cada companhia, com base nos últimos quatro anos (para calcular os dados de 2012, foi necessária a obtenção dos dados dos anos de 2008, 2009, 2010 e 2011), usando a Equação 1.

$$
\mathrm{ROA}_{\mathrm{it}}=\alpha \mathrm{i}+\beta \text { Retorno }_{\mathrm{it}}+\varepsilon_{\mathrm{it}}
$$

Em que: $\mathrm{ROA}_{i t}=$ Lucro líquido anual não consolidado sobre o ativo total inicial não consolidado da empresa i, no período t. O termo lucro líquido anual aqui utilizado é derivado do termo inglês earnings, cujo significado é o resultado contábil, podendo ser positivo ou negativo (YIP; YOUNG, 2012). Assim, para o contexto brasileiro, adotou-se o termo lucro líquido, conforme definido a partir das IFRS, representando o resultado contábil positivo ou negativo das empresas. $=$ Retorno médio anual da empresa $\mathrm{i}$ no período $t$, calculado com base no preço de fechamento, ajustado para dividendos e desdobramentos. Assim, esses indicadores foram calculados para cada empresa, individualmente, independente de seu setor e sobre os valores não consolidados.

Após a estimação dos parâmetros das funções individuais, foi projetado o ROA esperado [E(ROA)] de cada empresa, com base nas regressões obtidas. Primeiro, estimou-se o ROA específico da companhia no período, de acordo com a Equação 2.

$$
\mathrm{E}(\mathrm{ROA}) \mathrm{ijt}=\alpha \mathbf{j}+\beta \hat{j} \text { Retornoit }
$$

Na sequência, foi calculado o E(ROA) da mesma empresa, com os estimadores das outras companhias do mesmo setor, conforme a Equação 3.

$$
\mathrm{E}(\mathrm{ROA})_{\mathrm{iit}}=\hat{\alpha}_{\mathrm{i}}+\hat{\beta}_{\mathrm{i}} \wedge \text { Retorno }_{\mathrm{it}}
$$

O objetivo dos procedimentos descritos para as equações 2 e 3 foi manter o evento econômico constante, usando os estimadores de uma companhia no evento da outra empresa. Dessa forma, a medida de comparabilidade foi calculada pela média da distância entre essas duas funções para cada ano $\left[\mathrm{E}\left(\mathrm{ROA}_{\mathrm{iit}}\right)\right.$ $\left.\mathrm{E}\left(\mathrm{ROA}_{\mathrm{ijt}}\right)\right]$ (FRANCO; KOTHARI; VERDI, 2011). Ainda segundo Franco, Kothari e Verdi (2011, quanto mais próximas forem as duas funções, maior será a comparabilidade entre as empresas. O cálculo da média de proximidade de cada função contábil por período (ano) foi realizado por meio da Equação 4.

$$
\mathrm{COMPB}_{\mathrm{ijt}}=-\frac{1}{4} \mathrm{x}+\sum_{\mathrm{t}-3}^{\mathrm{t}}\left|\mathrm{E}\left(\mathrm{ROA}_{\mathrm{iit}}\right)-\mathrm{E}\left(\mathrm{ROA}_{\mathrm{ijt}}\right)\right|
$$

Em que: $\mathrm{COMPB}_{\mathrm{ijt}}=$ representa uma medida de comparabilidade individual relativa da empresa $\mathrm{i}$, 
baseada na empresa j; $\mathrm{E}\left(\mathrm{ROA}_{\mathrm{iit}}\right)=$ representa o retorno sobre o ativo previsto da empresa $\mathrm{i}$, com base nos estimadores da empresa i e o retorno da empresa i no período t; e $\mathrm{E}\left(\mathrm{ROA}_{\mathrm{ijt}}\right)=$ representa o retorno sobre o ativo previsto da empresa $\mathrm{i}$, com base nos estimadores da empresa j e o retorno da empresa i no período t.

De acordo com Franco, Kothari e Verdi (2011), quanto maior o valor obtido em $\mathrm{COMPB}_{\mathrm{ij}, \mathrm{t}}$ maior é a comparabilidade entre as empresas, já que a medida de comparabilidade (Equação 4) indica a distância média entre as funções de duas empresas isoladas. Adicionalmente, a média originada na $\mathrm{COMPB}_{\mathrm{ijt}}$ foi multiplicada por -1, para que um valor mais alto representasse que a empresa possui uma maior comparabilidade dos relatórios financeiros (YIP; YOUNG, 2012; RIBEIRO et al., 2016).

Para se obter uma medida individual de comparabilidade dos relatórios financeiros, comparando com os pares do setor, foi necessário calcular a média dessas distâncias entre as companhias de referência, conforme a Equação 5 .

$$
\mathrm{COMPB}_{\mathrm{it}}=\frac{\mathrm{Compb}_{\mathrm{ijt}}}{\mathrm{n}}
$$

Em que: $\mathrm{COMPM}_{\mathrm{it}}=$ Medida de comparabilidade dos relatórios financeiros individual de cada companhia em relação aos seus pares do setor; $\mathrm{COMPB}_{\mathrm{ijt}}=$ Medida de comparabilidade dos relatórios financeiros individual, relativa de cada par de empresa; e $\mathrm{N}$ = número de companhias no setor (ou sendo comparadas).

Para Franco, Kothari e Verdi (2011), quanto mais próximo de zero for a medida $\mathrm{COMPM}_{\mathrm{it}}$, maior será o nível de comparabilidade dos relatórios financeiros individual da empresa, em comparação às demais empresas que pertencem ao mesmo setor.

\subsection{Mensuração da variável volume anormal de negociação}

Segundo Alves, Pope e Young (2011), diferente das medidas diretas baseadas no mercado de capitais, como o preço, o volume de negociação fornece uma medida da resposta do mercado a um anúncio e, como tal, é capaz de capturar transferências de informações positivas e negativas. O volume de negociação produz insights a respeito da assimetria de informação e das divergências dos investidores que são de particular interesse para os pesquisadores e formuladores de políticas contábeis (BAMBER; BARRON; STEVENS, 2011). Assim, uma medida não assinalada, como volume de negociação é particularmente apropriada, por capturar melhor as informações transferidas em torno do conteúdo dos anúncios dos resultados das companhias, pois, mesmo que a empresa divulgue outros relatórios junto com a informação dos resultados, o volume de negociação anormal consegue capturar esses efeitos da divulgação concomitante de outros relatórios financeiros (KIM; VERRECCHIA, 1991; BAMBER; BARRON; STEVENS, 2011; BYARD; MASHRUWALA; SUH, 2017).

Em relação ao volume anormal de negociação, primeiro foi estabelecida uma janela de estimação, com base em 50 pregões, contados a partir de dez pregões ocorridos antes do evento, para que não houvesse influência do evento na janela de estimação (REINA et al., 2020). Ou seja, caso o evento tenha ocorrido na data 0 , a janela de evento vai do período -1 ao +1 (três dias), conforme ilustra a Figura 1 . Assim, sendo a janela de estimação vai do período -60 ao -11, totalizando 50 pregões (FOLSTER, 2018; BYARD; MASHRUWALA; SUH, 2017; YIP; YOUNG, 2012). Além disso, não foi incluído o período do evento em si, na janela de estimação, para não influenciar o evento (MACKINLAY, 1997; MELLACI; PETROKAS; FAMÁ, 2012; FERNANDES, 2013). A escolha de 50 pregões foi estabelecida para permitir que outros eventos não interferissem no evento estudado, considerando que as projeções de resultados das companhias, geralmente, são divulgadas no início de cada ano (FOLSTER, 2018).

Figura 1 Janela de Estimação e de Evento

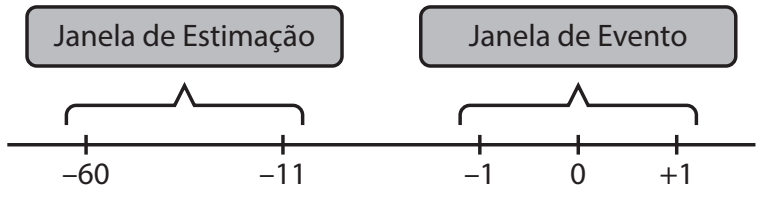

Fonte: Reina et al. (2020, p. 8)

Inicialmente, foi obtida a data de divulgação dos resultados pelas empresas. A partir dessas datas, foram identificados os volumes diários de negociação, 
com base no número de ações negociadas dividido pelo número total de ações em circulação (BYARD; MASHRUWALA; SUH, 2017. Isso foi feito, em primeiro lugar, para o estabelecimento do volume de negociação médio esperado, em janelas de um período que é considerado de não evento (janela de estimação), de acordo com Bamber, Barron e Stevens (2011). Isto é, o período de não eventos é considerado a partir de 60 dias de negociação, antes da data do anúncio dos resultados das companhias, para dez dias de negociação antes da data do anúncio (período -60 ao -11 , totalizando 50 pregões) (BAMBER; BARRON; STEVENS, 2011, BYARD; MASHRUWALA; SUH, 2017). Em segundo lugar, o procedimento foi adotado para a janela de eventos (período -1 ao +1 , três dias, considerando 0 como o dia do evento). As datas dos anúncios consideradas foram a da primeira divulgação da empresa. Assim, de acordo com Bamber, Barron e Stevens (2011), o volume de negociação anormal (VOL) no período de anúncio pode ser calculado conforme Equação 6.

$$
\mathrm{VOL}_{\mathrm{ijt}}=\mathrm{VNP}_{\mathrm{ijt}}-\mathrm{VNE}_{\mathrm{ijt}}
$$

Em que: $\mathrm{VOL}_{\mathrm{ijt}}=$ representa $\mathrm{o}$ volume anormal de negociação para as empresas i e j (empresas anunciadoras e empresas não anunciadoras) no período t; $\mathrm{VNP}_{\mathrm{ijt}}=$ representa o volume médio de negociação do período na janela de estimação de 50 pregões ao longo dos dias $\mathrm{t}-60$ até $\mathrm{t}-11$; $\mathrm{eVNE}_{\mathrm{ijt}}=$ indica o volume médio de negociação esperado para as empresas i e $\mathrm{j}$, ao longo dos dias $\mathrm{t}-1,0 \mathrm{e} \mathrm{t}+1$ na janela de eventos de três dias (conforme Figura 1).

O volume diário de negociação, tanto na janela de estimação como na janela de eventos, é a soma do número de ações negociadas (ordinárias e preferenciais), escalonado pelo número de ações, em circulação na data do anúncio de resultados das empresas que anunciam primeiro. Assim, quanto menor for essa diferença percentual no volume de negociação entre a janela de estimação e a janela de eventos das empresas, maior será a transferência de informação dessa empresa em relação às demais do setor (REINA et al., 2020)

\subsection{Variáveis utilizadas na pesquisa}

Segundo Alves, Pope e Young (2011), existe pouca teoria que oriente a seleção mais apropriada de variáveis de controle. Nesse sentido, seguindo a literatura (WANG, 2014; FRANCIS; PINNUCK; WATANABE, 2014; WEICHAO; DAOGUANG; SIYI, 2018; FRANCO; HOU; MA, 2019), foram escolhidas, como variáveis de controle: Atraso dos anúncios de resultados $\left(\mathrm{RLAG}_{\mathrm{ijt}}\right)$; Tamanho das empresas $\left(\mathrm{TAM}_{\mathrm{ijt}}\right)$; Alavancagem das empresas $\left(\mathrm{ALAV}_{\mathrm{ijt}}\right)$; Valor absoluto da diferença na relação MTB (MTBDIF $\left.{ }_{\mathrm{ijt}}\right)$; Endividamento das empresas $\left(\mathrm{END}_{\mathrm{ijt}}\right)$; Tipo de resultado anunciado (DPREJ $\mathrm{J}_{\mathrm{ij}}$ ); Setor econômico (DSETOR $\mathrm{Dit}_{\mathrm{it}}$ ).

Em que: a variável RLAG $_{\mathrm{ijt}}$ representa o atraso do anúncio de resultados das empresas i e j no período t, mensurado pelo log natural de dias, a partir de $1^{\circ} \mathrm{de}$ janeiro até a data do anúncio de resultados de cada empresa mais um; a variável $\mathrm{TAM}_{\mathrm{ijt}}$ é uma proxy para representar o tamanho da empresa. O tamanho representa o logaritmo natural do ativo total das empresas que anunciam posteriormente, calculado no período t; a variável $A L A V_{i j t}$ representa a relação do passivo total no final do exercício das empresas i e j, no período t em relação ao ativo total dessas empresas; a variável MTBDIF $_{\mathrm{ijt}}$ representa o valor absoluto da diferença na relação MTB entre a empresa i e a empresa j, no setor em torno do período t; a variável de controle $\mathrm{END}_{\mathrm{ijt}}$ é uma proxy para o endividamento das empresas i e j no período t, quanto ao risco de inadimplência, ou seja, as empresas altamente endividadas tendem a estar associadas ao alto risco. Esse índice de endividamento é obtido a partir da relação do total de dívida bruta com o passivo total das companhias; a variável de controle DPRE Jit $_{\text {it }}$ assume o valor igual a 1 , se a empresa divulgar prejuízo em seus anúncios de resultado; e assume 0 , o contrário; e, a variável de controle $\mathrm{DSETOR}_{\mathrm{ijt}}$ representa o setor econômico a que pertence cada empresa. Dessa forma, a variável DSETOR $\mathrm{ijt}_{\mathrm{t}}$ é representada por um conjunto de variáveis binárias (dummy), que assumem valor igual a 1 para as empresas que participam de determinado setor, e igual a 0 para as demais empresas de outros setores. Assim é calculada uma variável categórica nominal, com identificação dos 12 setores econômicos.

O volume anormal de negociação (VOL) indica a transferência de informação ocorrida em torno dos 
anúncios dos resultados das empresas. Assim, quanto menor for a diferença percentual no volume de negociação das empresas entre a janela de estimação e a janela do evento, maior será a transferência de informação dessa empresa em relação às demais empresas do setor (BYARD; MASHRUWALA; SUH, 2017; WEICHAO; DAOGUANG; SIYI, 2018). Nesse sentido, foi calculado o volume anormal de negociação (VOL), tanto para as empresas não anunciadoras $\left(\mathrm{VOL}_{\mathrm{ENA}, \mathrm{ijt}}\right)$ como para as empresas anunciadoras $\left(\mathrm{VOL}_{\mathrm{EA}, \mathrm{jit}}\right) \mathrm{em}$ todos os setores. Desse modo, seguindo a literatura, a variável dependente é: $\mathrm{VOL}_{\mathrm{ENA}, \mathrm{ijt}}$.

Diante do exposto, o VOL $\mathrm{VNNA}_{\mathrm{E}, \mathrm{it}}$ constitui uma variável dependente, que representa o volume anormal de negociação da empresa $j$ (não anunciadora ENA), em torno do anúncio de resultados no período t da empresa i (anunciadora - EA), e o VOL $\mathrm{VA}_{\mathrm{A}, \mathrm{ji}}$ representa uma variável de teste, indicadora do volume anormal de negociação da empresa i (anunciadora A), no período t do anúncio de resultados da própria empresa i.

As variáveis de testes, adotadas neste estudo, estão relacionadas à transferência de informação no mercado de capitais, de acordo com a literatura (FOSTER, 1981; FREEMAN; TSE, 1992; FIRTH, 1996; THOMAS; ZHANG, 2008; PANDIT; WASLEY; ZACH, 2011; FRANCO; KOTHARI; VERDI, 2011; ALVES; POPE; YOUNG, 2011; FRANCIS; PINNUCK; WATANABE, 2014; BYARD et al., 2018; HENRY et al., 2020; WEICHAO; DAOGUANG; SIYI, 2018; FRANCO; HOU; MA, 2019). Com base nas características das companhias da amostra, foram testadas as seguintes variáveis de testes: Comparabilidade média dos relatórios financeiros $\left(\mathrm{COMPM}_{\mathrm{ijt}}\right)$; Cobertura de analistas de mercado de capitais $\left(\mathrm{DCOBA}_{\mathrm{ijt}}\right)$; Mesma empresa de auditoria $\left(\right.$ DMEAUD $\left._{\mathrm{ijt}}\right)$; e, Volume anormal de negociação da empresa anunciadora $\left(\mathrm{VOL}_{\mathrm{EA}, \mathrm{it}}\right)$.

Por fim, seguindo a literatura (FOSTER, 1981; FREEMAN; TSE, 1992; FIRTH, 1996; THOMAS; ZHANG, 2008; PANDIT; WASLEY; ZACH, 2011; (BYARD; MASHRUWALA; SUH, 2017; FRANCO; KOTHARI; VERDI, 2011; BYARD et al., 2018; HENRY et al., 2020; FRANCIS; PINNUCK; WATANABE, 2014; FRANCO; HOU; MA, 2019), para este estudo assumiu-se que: (i) a variável representa a comparabilidade média das empresas i e j, que divulgam seus resultados no período t, mensurada de acordo com o modelo de Franco, Kothari e Verdi (2011). De acordo com Franco, Kothari e Verdi (2011), quanto mais próximo de zero for o índice COMPM, maior será a comparabilidade da empresa em relação às demais empresas do setor; (ii) a quantidade de analistas que dão cobertura às companhias i e $\mathrm{j}$, no período $\mathrm{t}$, corresponde ao número de analistas disponível em 31 de dezembro de cada ano. Com isso, a cobertura de analistas $\mathrm{DCOBA}_{\mathrm{ijt}}$ é uma variável dummy igual a 1, quando a empresa i (anunciadora) apresentar a maior quantidade de analistas que dão cobertura às empresas, em relação às demais empresas (não anunciadoras) do setor, 0 , o contrário; e (iii) a variável dummy DMEAUD $\mathrm{D}_{\mathrm{ijt}}$ recebe indicador igual a 1 , se as empresas i e j compartilham a mesma empresa de auditoria no setor, e 0 , caso contrário. Isto é, quando as empresas i e j são auditadas pela mesma empresa de auditoria, a empresa i recebe o indicador 1 , e as demais empresas do setor (empresas $\mathrm{j}$ ) recebem o indicador 0. Quando a empresa i e as demais empresas do setor (empresas j) não são auditadas pela mesma empresa de auditoria, a empresa i recebe indicador 0 , e as demais empresas (empresas j do setor) recebem indicador 1.

\subsection{Mensuração da transferência de informação}

A Equação 7 foi adotada como modelo inicial de mensuração da transferência de informação, com base nos modelos de Byard, Mashruwala e Suh (2017) e Weichao, Daoguang e Siyi (2018), e modificada para mensurar as hipóteses deste estudo. Dessa forma, a Equação 7 foi alterada para testar a associação da influência da comparabilidade dos relatórios financeiros na transferência de informação, em função das seguintes variáveis: (i) cobertura de analistas de mercado; e (ii) firmas semelhantes de auditoria.

$$
\begin{aligned}
\mathrm{VOL}_{\mathrm{ENA}, \mathrm{ijt}}= & \beta_{0}+\beta_{1} \cdot \mathrm{DPOST}_{\mathrm{EA}, \mathrm{it}}+\beta_{2} \cdot \mathrm{VOL}_{\mathrm{EA}, \mathrm{it}} \\
& +\beta_{3} \cdot \operatorname{VOL}_{\mathrm{EA}, \mathrm{it}} \times \operatorname{DPOST}_{\mathrm{EA}, \mathrm{it}} \\
& +\Sigma \beta_{\mathrm{j}} \times \operatorname{CONTROLES~}_{\mathrm{i}, \mathrm{t}}+\varepsilon_{\mathrm{i}, \mathrm{t}}
\end{aligned}
$$


A divulgação das empresas que possuem maior cobertura de analistas de mercado pode influenciar a transferência de informação em torno dos anúncios de resultados, pois níveis maiores de cobertura dos analistas pode ser um forte preditor de desempenho futuro das empresas lucrativas ou não. Diante disso, a Equação 8 tem por objetivo testar a relação entre as seguintes variáveis: (i) comparabilidade dos relatórios financeiros; (ii) volume anormal de negociação; e (iii) a cobertura de analistas de mercado.

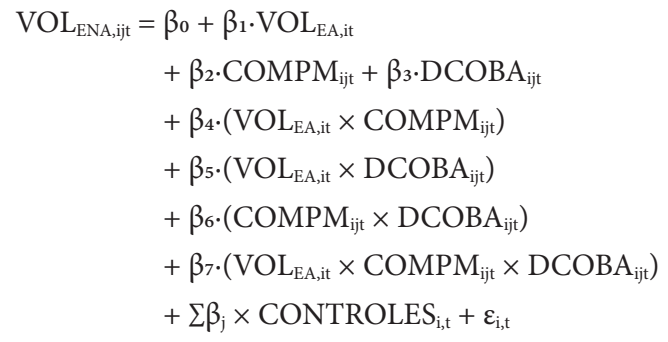

Em que: $\mathrm{DCOBA}_{\mathrm{ijt}}=$ é uma variável dummy, que representa a quantidade de analistas que dão cobertura às empresas $i$ (anunciadoras) e $j$ (não anunciadoras) no setor, no período t. Assim, essa variável é igual a 1 quando a empresa i (anunciadora) apresenta a maior quantidade de analistas que dão cobertura às empresas em relação às demais empresas (não anunciadoras) do setor; 0 , o contrário. A cobertura de analistas se refere à quantidade de analistas que dão cobertura às empresas disponível em 31 de dezembro de cada ano.

$\mathrm{Na}$ Equação 8, o coeficiente de interesse é $\beta_{7}$, que demonstra a associação da comparabilidade média das empresas com a transferência de informação do volume anormal de negociação, em torno da cobertura de analistas das empresas. Assim, da interação entre $\mathrm{VOL}_{\mathrm{EA}, \mathrm{it}} \times \mathrm{COMPM}_{\mathrm{ijt}} \times \mathrm{DCOBA}_{\mathrm{ijt}}\left(\beta_{7}\right)$, poderá resultar um sinal positivo, indicando que o efeito da comparabilidade dos relatórios financeiros, na transferência de informação, é menor na empresa que possui maior cobertura de analistas em seu setor em relação às demais, ou poderá ser negativo, indicando que o efeito da comparabilidade sobre a transferência de informação independe da quantidade de analistas que acompanham as empresas.

A divulgação das empresas que são auditadas pela mesma empresa de auditoria que as demais empresas do setor pode influenciar a transferência de informação em torno dos anúncios de resultados, pois as recomendações das empresas de auditoria podem seguir um padrão, em função de as empresas pertencerem a um mesmo setor de atividade econômica. Dessa forma, a Equação 9 tem por objetivo testar a relação entre as seguintes variáveis: (i) comparabilidade dos relatórios financeiros; (ii) volume anormal de negociação; e (iii) compartilha a mesma empresa de auditoria.

$$
\begin{aligned}
\mathrm{VOL}_{\mathrm{ENA}, \mathrm{ijt}}= & \beta_{0}+\beta_{1} \cdot \mathrm{VOL}_{\mathrm{EA}, \mathrm{it}} \\
& +\beta_{2} \cdot \mathrm{COMPM}_{\mathrm{ijt}}+\beta_{3} \cdot \mathrm{DMEAUD}_{\mathrm{ijt}} \\
& +\beta_{4} \cdot\left(\mathrm{VOL}_{\mathrm{EA}, \mathrm{it}} \times \mathrm{COMPM}_{\mathrm{ijt}}\right) \\
& +\beta_{5} \cdot\left(\mathrm{VOL}_{\mathrm{EA}, \mathrm{it}} \times \mathrm{DMEAUD}_{\mathrm{ijt}}\right) \\
& +\beta_{6} \cdot\left(\mathrm{COMPM}_{\mathrm{ijt}} \times \mathrm{DMEAUD}_{\mathrm{ijt}}\right) \\
& +\beta_{7} \cdot\left(\mathrm{VOL}_{\mathrm{EA}, \mathrm{it}} \times \mathrm{COMPM}_{\mathrm{ijt}} \times \mathrm{DMEAUD}_{\mathrm{ijt}}\right) \\
& +\Sigma \beta_{\mathrm{j}} \times \mathrm{CONTROLES}_{\mathrm{i}, \mathrm{t}}+\varepsilon_{\mathrm{i}, \mathrm{t}}
\end{aligned}
$$

Em que: DMEAUD $D_{\mathrm{ijt}}$ é uma variável dummy, indicadora igual a 1 se as empresas i e j compartilham a mesma empresa de auditoria no setor, 0 , caso contrário. Assim, quando as empresas i e j são auditadas pela mesma empresa de auditoria, a empresa i recebe $\mathrm{o}$ indicador $1 \mathrm{e}$ as demais empresas do setor (empresas j) recebem o indicador 0. Quando a empresa i e as demais empresas do setor (empresas j) não são auditadas pela mesma empresa de auditoria, a empresa i recebe indicador 0 e as demais empresas (empresas $j$ do setor) recebem indicador 1 .

Na Equação 9, o coeficiente de interesse é , que associa a comparabilidade média das empresas com a transferência de informação, por meio do volume anormal de negociação em torno da mesma empresa de auditoria. Assim, da interação entre $\mathrm{VOL}_{\mathrm{EA}, \mathrm{it}} \times$ $\mathrm{COMPM}_{\mathrm{ijt}} \times$ DMEAUD $_{\mathrm{ijt}}\left(\beta_{7}\right)$, poderá resultar um sinal positivo, indicando que o efeito da comparabilidade dos relatórios financeiros na transferência de informação é menor na empresa que é auditada pela mesma empresa de auditoria que as demais empresas no setor, ou poderá ser negativo, indicando que o 
efeito da comparabilidade sobre a transferência de informação independe da empresa de auditoria.

\section{DESCRIÇÃO E ANÁLISE DOS REŞULTADOS}

Na Tabela 2, sumariza-se a estatística descritiva para as principais variáveis desta pesquisa. Assim, percebe-se que a variável dependente VOLena apre- sentou um valor médio de 0,1271 , mediana de 0,00001 e desvio padrão de 0,1252. De acordo com a Tabela 2, se observa um elevado desvio padrão para a variável COMPM, principalmente quando se analisam as medidas de dispersão dessas variáveis.

Tabela 2 Estatística descritiva das principais variáveis utilizadas na pesquisa

\begin{tabular}{|c|c|c|c|c|c|c|}
\hline Variáveis & $\mathbf{N}$ & Média & Mediana & Desvio Padrão & Mínimo & Máximo \\
\hline VOLena & 854 & 0,1271 & 0,00001 & 0,1252 & $-0,2842$ & 0,3867 \\
\hline VOLea & 854 & 0,1538 & 0 & 0,1398 & $-0,2888$ & 0,4240 \\
\hline COMPM & 854 & 0,8172 & $-0,5385$ & 19,1765 & $-36,4712$ & 57,3786 \\
\hline TAM & 854 & 14,8889 & 15,2252 & 1,8672 & 8,8156 & 17,7540 \\
\hline ALAV & 854 & 0,7356 & 0,6161 & 0,4598 & 0,2176 & 2,1978 \\
\hline MTBDIF & 854 & 1,2701 & 0,8512 & 1,3105 & 0,0733 & 5,4966 \\
\hline END & 854 & 0,4998 & 0,5491 & 0,2409 & 0 & 0,8563 \\
\hline RLAG & 854 & 4,2848 & 4,3820 & 0,28612 & 2,8903 & 5,7776 \\
\hline
\end{tabular}

Fonte: Dados da pesquisa

O resultado médio, obtido para a variável COMPM, com base nas empresas pares no setor, é de 0,8172 (Tabela 3). Com relação aos setores econômicos, verificou-se que existem diferenças aparentes da COMPM entre os diferentes setores. O setor Fábrica de equipamentos de transporte apresentou os maiores níveis de comparabilidade média, no valor de 0,2125 , enquanto o setor de Indústria de alimentos apresentou o menor nível de comparabilidade média, no valor de 16,5873 .

Na Tabela 3, expõe-se, ainda, o comportamento da variável COMPM segregada entre os setores econômicos investigados na pesquisa. As medidas foram calculadas com base na comparabilidade individual média de todas as empresas que compõem a amostra. Observa-se uma variabilidade expressiva da comparabilidade entre os setores, quando se compara o desvio padrão entre eles. Tal variabilidade no desvio padrão vai do maior desvio padrão, de 38,3548 , no setor de Indústria de produtos de metal, até o menor desvio padrão, de 2,6912, no setor Imobiliário. Esses resultados sugerem que, mesmo as empresas operando em seus setores, num ambiente econômico com características similares em nível de país e reguladas por um mesmo conjunto de normas (IFRS), num período de adoção obrigatória das IFRS, o nível de comparabilidade entre esses setores ainda pode ser melhorado.

Para testar se as diferenças aparentes são significativas estatisticamente, foi realizada a análise de variância. O teste de ANOVA (Tabela 3 ) sugere que existem diferenças estatisticamente significativas nos níveis de comparabilidade entre as empresas, de acordo com a sua distribuição por setores econômicos. Tal perspectiva reforça os achados do estudo de Ribeiro et al. (2016), de que nem todas as empresas do mesmo setor seguem idênticas formas de reconhecimento de suas movimentações contábeis, independentemente de estarem sob um conjunto único de normas contábeis.

O setor econômico de Serviços de utilidade pública foi o que apresentou maior transferência 
de informação, em função do seu volume anormal de negociação em relação aos demais setores. Essa transferência de informação pode estar relacionada à quantidade de empresas que fazem parte desse setor, considerando que ele representa mais de $27 \%$ das empresas que compõem a amostra. Cabe aqui ressaltar que essa transferência de informação é mensurada pela diferença percentual de negociação das ações entre as janelas de estimação e as janelas de eventos, com base nas datas dos anúncios das companhias. A maior quantidade de anúncios de resultados tende a produzir maior reação no mercado de atuação dessas empresas.

Outrossim, a maior reação identificada nos volumes anormais de negociação entre as companhias que anunciam seus resultados posteriormente pode, também, estar relacionada às características dos subsetores que compõem o setor de Serviços de utilidade pública. Esses subsetores operam sob regulação própria, além de observarem o cumprimento das normas referendadas pela CVM. Nesse sentido, quando as companhias operam num ambiente altamente regulado, a tendência é que exista maior quantidade de informações disponíveis aos usuários sobre essas empresas do que nas empresas dos demais setores. Esse resultado corrobora a perspectiva de Habib, Hasan e Al-Hadi (2017), ao defenderem que maior quantidade de informação disponível pode reduzir as incertezas no ambiente de operação das empresas. Além disso, essa reação nos volumes anormais de negociação sugere que a eficiência na transferência de informação nas empresas do setor de Serviços de utilidade pública é maior do que nos anúncios de resultados dos demais setores.

$\mathrm{Na}$ Tabela 4, apresenta-se o comportamento da variável VOLena, segregada entre os setores econômicos investigados. Observa-se que o resultado da média, obtido para a variável VOLena, com base nas empresas do setor, foi 0,127 de variabilidade.

Tabela 3 Estatística Descritiva da Comparabilidade por Setor

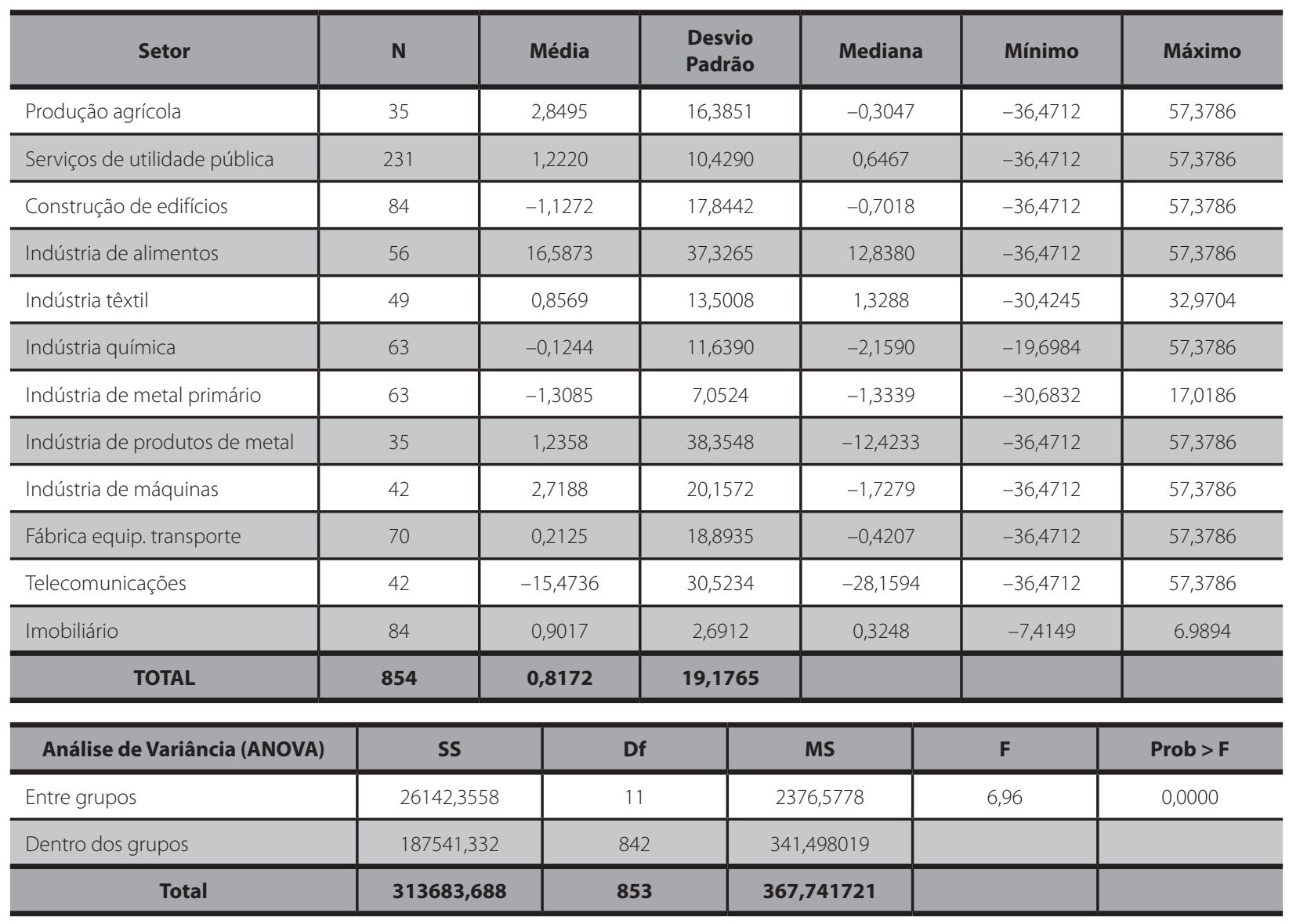

Fonte: Dados da pesquisa 
Com relação aos setores econômicos, verificou-se que existem diferenças aparentes da VOLena entre os diferentes setores. Para testar se as diferenças aparentes são significativas estatisticamente, foi realizada a análise de variância. Assim, o teste de ANOVA (Tabela 4) evidenciou que existem diferenças estatisticamente significativas nos níveis de VOLena, entre as empresas, de acordo com a sua distribuição por setores econômicos. Esse resultado mostra que o setor exerce influência no volume anormal de negociação entre as companhias que anunciam posteriormente.

A partir da Tabela 5, onde se apresenta o comportamento da variável VOLena por ano, é possível observar que, em termos médios, a VOLena apresentou uma pequena variabilidade durante o período investigado. Desta forma, com o intuito de testar se essas diferenças aparentes são significativas estatisticamente, foi realizada a análise de variância, tendo o teste de ANOVA (Tabela 5) demonstrado que não existem diferenças estatisticamente significativas nos níveis de VOLena no período investigado. Esse resultado sugere que o volume anormal de negociação das empresas que anunciam seus resultados posteriormente não está associado, diretamente, à determinada quantidade de anos em que as empresas negociam e/ou operam no mercado.

Na Tabela 6, apresenta-se o comportamento da variável VOLea, segregada entre os setores econômicos investigados. O resultado médio obtido para a variável VOLea, com base nas empresas do setor foi 0,153 . Com relação aos setores econômicos, verificou-se que existem diferenças aparentes da VOLea entre os diferentes setores.

Para testar se as diferenças aparentes são significativas estatisticamente, foi realizada a análise de variância, em que o teste de ANOVA (Tabela 6) mostrou que existem diferenças estatisticamente significativas nos níveis de VOLea entre as empresas, de acordo com a sua distribuição por setores econômicos. Esse resultado mostra que o setor pode exercer influência no volume anormal de negociação entre as companhias que anunciam primeiro. A mesma influência também se observou entre as empresas não anunciadoras. Apesar disso, a média geral dos setores foi menor entre as empresas que anunciam posteriormente, indicando que o volume anormal de negociação entre os setores, com empresas que anunciam posteriormente, é maior do que entre os setores com empresas que anunciam primeiro.

A partir da Tabela 7, onde se apresenta o comportamento da variável VOLea por ano, é possível observar que, em termos médios, a VOLea apresentou variabilidade durante o período investigado. Assim, com o intuito de testar se as diferenças aparentes são significativas estatisticamente, foi realizada a análise de variância.

O teste de ANOVA (Tabela 7) apontou que existem diferenças estatisticamente significativas nos níveis de VOLea, no período investigado. Esse resultado demonstra que o volume anormal de negociação das empresas que anunciam seus resultados primeiro pode ser influenciado pela quantidade de tempo que uma empresa opera no mercado de capitais. Assim, quando se analisam sete anos, como na presente pesquisa, percebe-se a existência de um comportamento diferente na reação dos investidores, dado que, na análise das empresas que anunciam posteriormente, não foi identificada a mesma condição de influência do período analisado, em relação ao volume anormal de negociação.

\subsection{Análise da transferência de informação na perspectiva cobertura de analistas}

Para testar $H_{1}$, foi estimado o modelo de regressão, conforme a Equação (8), com a abordagem POLS. Foi realizado o teste de Breusch-Pagan para heterocedasticidade $(\mathrm{BG}=22,67$; $\mathrm{p}$-valor $<0,000) \mathrm{e}$, com isso, rejeitou-se a hipótese de homogeneidade dos resíduos, indicando que o modelo deverá ser estimado, considerando erros-padrão robustos quanto à heterocedasticidade. Em seguida, verificou-se a estatística do fator de inflação da variância (FIV), sendo que o valor médio identificado foi 2,71 , variando entre 1,30 (COBA e MTBDIF) e 6,84 (SETOR 2). Portanto, considera-se que não há problemas de multicolinearidade nesse modelo. O teste RESET de Ramsey ( $\mathrm{F}=0,35$; $\mathrm{p}$-valor $<0,7870$ ) indicou que o modelo possui problema de especificação.

Foram realizados os testes de especificação de Chow $(\mathrm{F}=0,78$; $\mathrm{p}$-valor $<0,9539)$, Breusch-Pagan $(\mathrm{BP}=0,00 ; \mathrm{p}$-valor $<1,000)$ e Hausman e, com isso, foram aceitas as hipóteses nulas. Esse resultado 
Tabela 4 Estatística Descritiva da VOLena por Setor Econômico

\begin{tabular}{|c|c|c|c|c|c|c|}
\hline Setor & $\mathbf{N}$ & Média & $\begin{array}{l}\text { Desvio } \\
\text { Padrão }\end{array}$ & Mediana & Mínimo & Máximo \\
\hline Produção agrícola & 35 & $-0,005$ & 0,102 & $-0,000$ & $-0,284$ & 0,386 \\
\hline Serviços de utilidade pública & 231 & $-0,000$ & 0,101 & 0,000 & $-0,284$ & 0,386 \\
\hline Construção de edifícios & 84 & 0,011 & 0,181 & 0,000 & $-0,284$ & 0,386 \\
\hline Indústria de alimentos & 56 & $-0,002$ & 0,069 & 0 & $-0,284$ & 0,169 \\
\hline Indústria têxtil & 49 & 0,084 & 0,154 & 0,012 & $-0,284$ & 0,386 \\
\hline Indústria química & 63 & $-0,005$ & 0,077 & 0,000 & $-0,284$ & 0,386 \\
\hline Indústria de metal primário & 63 & 0,017 & 0,056 & 0,000 & $-0,007$ & 0,311 \\
\hline Indústria de produtos de metal & 35 & $-0,003$ & 0,107 & 0,000 & $-0,284$ & 0,386 \\
\hline Indústria de máquinas & 42 & 0,001 & 0,040 & 0,000 & $-0,125$ & 0,125 \\
\hline Fábrica equip. transporte & 70 & 0,031 & 0,184 & 0,000 & $-0,284$ & 0,386 \\
\hline Telecomunicações & 42 & 0,017 & 0,146 & 0 & $-0,284$ & 0,386 \\
\hline Imobiliário & 84 & 0,029 & 0,148 & 0,000 & $-0,284$ & 0,386 \\
\hline TOTAL & 854 & 0,127 & 0,125 & & & \\
\hline Análise de Variância (ANOVA) & SS & & & MS & $\mathbf{F}$ & Prob $>$ F \\
\hline Entre grupos & 0,4017 & & & 0,0365 & 2,37 & 0,0070 \\
\hline Dentro dos grupos & 12,988 & & & 0,0154 & & \\
\hline Total & 13,390 & & & 0,1569 & & \\
\hline
\end{tabular}

Fonte: Dados da pesquisa

Tabela 5 Estatística Descritiva da VOLena Ano

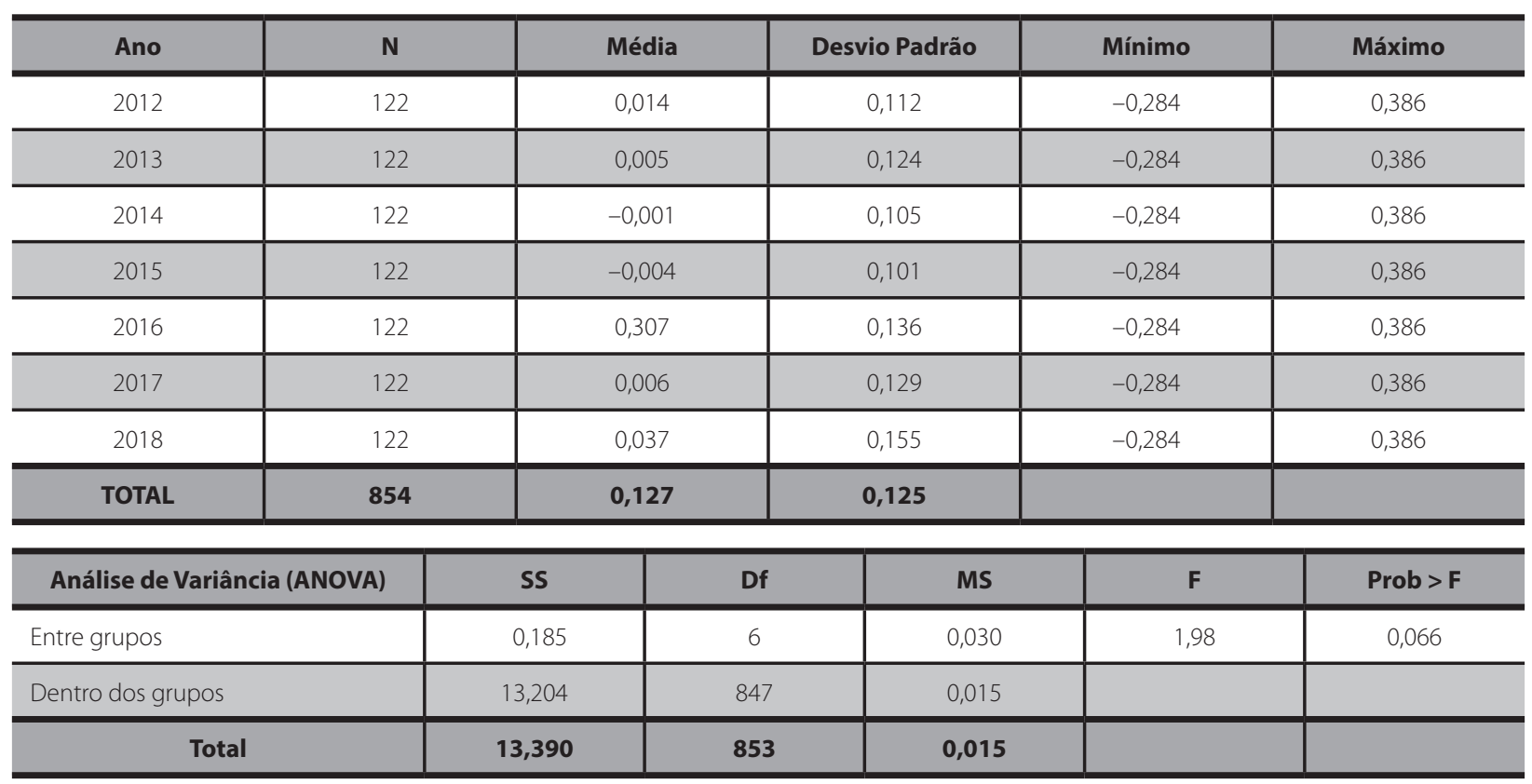

Fonte: Dados da pesquisa 
Tabela 6 Estatística Descritiva da VOLea por Setor Econômico

\begin{tabular}{|c|c|c|c|c|c|c|}
\hline Setor & $\mathbf{N}$ & Média & $\begin{array}{l}\text { Desvio } \\
\text { Padrão }\end{array}$ & Mediana & Mínimo & Máximo \\
\hline Produção agrícola & 35 & $-0,000$ & 0,003 & $-0,000$ & $-0,000$ & 0,000 \\
\hline Serviços de utilidade pública & 231 & 0,080 & 0,148 & 0,000 & $-0,000$ & 0,424 \\
\hline Construção de edifícios & 84 & $-0,007$ & 0,219 & $-0,016$ & $-0,288$ & 0,424 \\
\hline Indústria de alimentos & 56 & 0,021 & 0,054 & $-0,000$ & $-0,001$ & 0,153 \\
\hline Indústria têxtil & 49 & 0,075 & 0,146 & 0,208 & $-0,022$ & 0,424 \\
\hline Indústria química & 63 & $-0,412$ & 0,101 & 0,000 & $-0,288$ & 0,000 \\
\hline Indústria de metal primário & 63 & 0,000 & 0,000 & $-0,000$ & $-0,000$ & 0,001 \\
\hline Indústria de produtos de metal & 35 & $-0,084$ & 0,148 & $-0,084$ & $-0,288$ & 0,117 \\
\hline Indústria de máquinas & 42 & $-0,008$ & 0,034 & $-0,000$ & $-0,078$ & 0,117 \\
\hline Fábrica equip. transporte & 70 & 0,005 & 0,179 & 0,000 & $-0,021$ & 0,402 \\
\hline Telecomunicações & 42 & 0,060 & 0,150 & $-0,000$ & $-0,000$ & 0,424 \\
\hline Imobiliário & 84 & $-0,080$ & 0,126 & $-0,001$ & $-0,288$ & 0,001 \\
\hline TOTAL & 854 & 0,153 & 0,139 & & & \\
\hline Análise de Variância (ANOVA) & SS & & & MS & $\mathbf{F}$ & Prob $>$ F \\
\hline Entre grupos & 2,671 & & & 0,242 & 14,60 & 0,000 \\
\hline Dentro dos grupos & 14,007 & & & 0,016 & & \\
\hline Total & 16,678 & & & 0,019 & & \\
\hline
\end{tabular}

Fonte: Dados da pesquisa

Tabela 7 Estatística Descritiva da VOLea por Ano

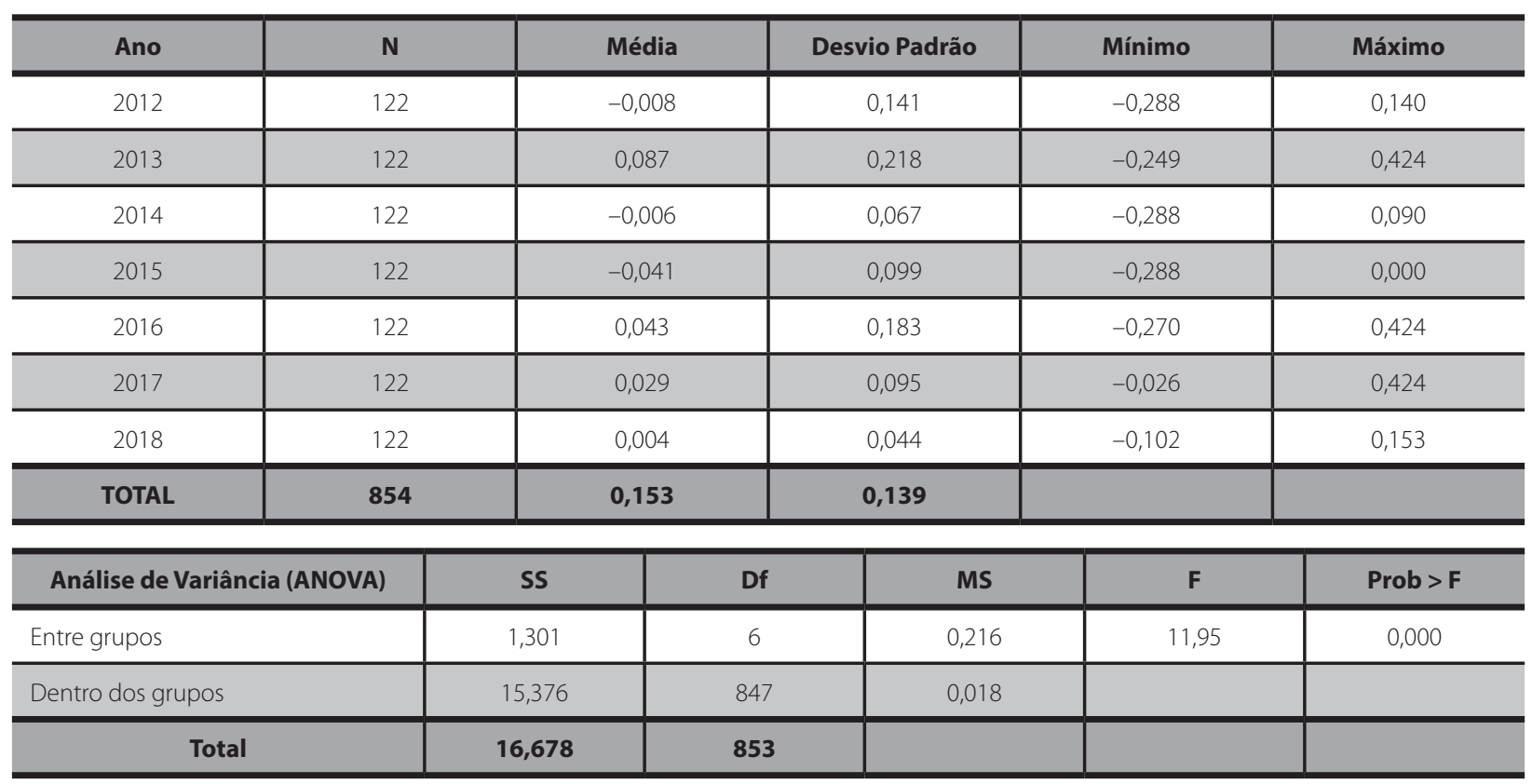

Fonte: Dados da pesquisa 
Tabela 8 Modelo de Transferência de Informação e Cobertura dos Analistas

\begin{tabular}{|c|c|c|c|c|c|c|}
\hline \multirow[b]{2}{*}{ Variável dependente: VOLena } & \multicolumn{3}{|c|}{ Com outliers } & \multicolumn{3}{|c|}{ Sem outliers } \\
\hline & $\begin{array}{l}\text { Pooled } \\
\text { (POLS) }\end{array}$ & EA & EF & $\begin{array}{l}\text { Pooled } \\
\text { (POLS) }\end{array}$ & EA & EF \\
\hline Intercepto & $-0,022$ & $-0,022$ & $-0,178$ & $-0,036$ & $-0,036$ & $-0,056$ \\
\hline VOLea & $0,343^{* * *}$ & $0,343^{* * *}$ & $0,349^{* * *}$ & $0,327^{* * *}$ & $0,327^{* * *}$ & $0,356^{* * *}$ \\
\hline COMPM & 0,000 & 0,000 & 0,000 & 0,000 & 0,000 & 0,000 \\
\hline COBA & $-0,000$ & $-0,000$ & 0,002 & 0,005 & 0,005 & 0,011 \\
\hline VOLea*COMPM & $0,005^{*}$ & $0,005^{*}$ & $0,006^{* *}$ & $0,011^{* * *}$ & $0,011^{* * *}$ & $0,014^{* * *}$ \\
\hline VOLea*COBA & $-0,261^{* * *}$ & $-0,261^{* * *}$ & $-0,267^{* * *}$ & $-0,272^{* * *}$ & $-0,272^{* * *}$ & $-0,309^{* * *}$ \\
\hline $\mathrm{COMPM}^{*} \mathrm{COBA}$ & $-0,000$ & $-0,000$ & $-0,000$ & $-0,000$ & $-0,000$ & $-0,000$ \\
\hline VOLea*COMPM*COBA & $-0,005$ & $-0,005$ & $-0,006^{*}$ & $-0,010^{* *}$ & $-0,010^{* *}$ & $-0,012^{* *}$ \\
\hline ALAV & 0,022 & $0,022^{*}$ & 0,041 & 0,004 & 0,004 & 0,005 \\
\hline TAM & $-0,001$ & $-0,001$ & 0,004 & $-0,004$ & $-0,004$ & $-0,008$ \\
\hline MTBDIF & $-0,001$ & $-0,001$ & 0,000 & 0,001 & 0,001 & 0,002 \\
\hline END & 0,015 & 0,015 & 0,042 & 0,019 & 0,019 & 0,055 \\
\hline RLAG & 0,003 & 0,003 & 0,017 & 0,015 & 0,015 & 0,032 \\
\hline DPREJ & $0,018^{*}$ & 0,018 & 0,013 & 0,008 & 0,008 & $-0,006$ \\
\hline 2.Serviços utilidade pública & 0,000 & 0,000 & & 0,005 & 0,005 & \\
\hline 3.Construção de edifícios & $-0,004$ & $-0,004$ & & $-0,026$ & $-0,026$ & \\
\hline 4. Indústria de alimentos & $-0,006$ & $-0,006$ & & $-0,005$ & $-0,005$ & \\
\hline 5. Indústria têxtil & $0,050^{*}$ & $0,050^{* *}$ & & 0,023 & 0,023 & \\
\hline 6. Indústria química & 0,003 & 0,003 & & 0,001 & 0,001 & \\
\hline 7.Indústria de metal primário & 0,018 & 0,018 & & 0,024 & 0,024 & \\
\hline 8.Indústria de produtos de metal & $-0,003$ & $-0,003$ & & $-0,010$ & $-0,010$ & \\
\hline 9. Indústria de máquina & $-0,001$ & $-0,001$ & & 0,000 & 0,000 & \\
\hline $\begin{array}{l}\text { 10.Fábrica de equipamentos de } \\
\text { Transporte }\end{array}$ & 0,026 & $0,026^{*}$ & & $-0,010$ & $-0,010$ & \\
\hline 11. Telecomunicações & 0,009 & 0,009 & & 0,010 & 0,010 & \\
\hline 12. Mobiliário & $0,044^{*}$ & $0,044^{* *}$ & & 0,033 & 0,033 & \\
\hline $\begin{array}{l}\text { OBS } \\
R^{2} \\
R^{2} \text { ajustado } \\
\text { Est. F }\end{array}$ & $\begin{array}{c}854 \\
0,096 \\
0,0311 \\
3.019\end{array}$ & $\begin{array}{l}854 \\
0,096\end{array}$ & $\begin{array}{c}854 \\
0,067 \\
0,065 \\
3.576\end{array}$ & $\begin{array}{c}805 \\
0,097 \\
0,199 \\
3.488\end{array}$ & $\begin{array}{r}805 \\
0,097\end{array}$ & $\begin{array}{c}805 \\
0,086 \\
0,080 \\
4.865\end{array}$ \\
\hline
\end{tabular}

Nota: ${ }^{*} p<0.1 ;{ }^{* *} p<0.05 ;{ }^{* * *} p<0.01$

significa que a adequação do modelo com POLS foi aceita quando comparada com o modelo de EF e quando comparada com o modelo de EA. Dessa forma, optou-se pelo modelo com abordagem de mínimos quadrados ordinários (POLS), uma vez que ele foi indicado como sendo o mais adequado.

Os resultados dos modelos com e sem tratamento dos outliers são apresentados na Tabela 8. Cabe ressaltar que, foram considerados como outliers os 
índices de comparabilidade que se afastaram do índice "zero" no modelo proposto por Franco, Kothari e Verdi (2011). Nesta continuação, ao analisar a Tabela 8 , observa se uma relação positiva e não significativa entre a comparabilidade e o VOLena. Já a variável VOLea apresentou uma relação positiva e significativa, ocorrendo o mesmo com a variável multiplicativa VOLea $\times$ COMPM. Entretanto, a variável VOLea $\times$ COBA evidenciou uma relação negativa, porém significativa. Para essas variáveis, os resultados não divergiram substancialmente com a presença de outliers.

No que tange às variáveis de controle, os resultados não foram significativos quando se analisa o modelo sem outliers. Apesar disso, as variáveis DPREJ e o setor de indústria têxtil e mobiliário apresentaram uma relação positiva e significativa no modelo com outliers.

A finalidade do teste da hipótese $H_{1}$ era verificar se o aumento do volume anormal de negociação, em torno dos anúncios de resultados, experimentado por uma empresa que possui maior cobertura de analistas de mercado, está associado, positivamente, ao aumento da comparabilidade de seus relatórios financeiros. Nesse sentido, observou-se que a interação multiplicativa entre as variáveis VOLea $\times$ COMPM $\times$ COBA, no modelo com outliers, apresenta uma relação negativa e não significativa. Todavia, quando se analisou o modelo sem outliers, a interação dessas mesmas variáveis é significativa, mas ainda negativa, sugerindo que a hipótese $H_{1}$ não pode ser confirmada em sua totalidade. Esse resultado sugere que o aumento do volume anormal de negociação das empresas como forma de mensurar a eficiência na transferência de informação independe da quantidade de analistas que dão cobertura às empresas e que essa eficiência da transferência de informação pode ser ainda menor quando se inclui as empresas consideradas outliers.

Os resultados também apontaram que as variáveis COMPM e COBA, quando analisadas sozinhas, não apresentaram um efeito significativo no VOLena. Entretanto, quando se analisa a interação das variáveis VOLea com a COMPM e VOLea com COBA, percebe-se que a interação entre elas é significativa para ambos os modelos. O mesmo, porém, não ocorre na interação multiplicativa das variáveis VOLea $\times C O M P M$, acrescentando-se a essa interação a variável COBA, pois, apesar de significativa no modelo sem outliers, ainda continua negativa, indicando, assim, que o efeito da comparabilidade, na eficiência da transferência de informação, não depende totalmente da quantidade de analistas que acompanham as empresas.

\subsection{Análise da transferência de informação na perspectiva da mesma empresa de auditoria}

A fim de testar a hipótese $H_{2}$, foi estimado o modelo de regressão, conforme a Equação (9), com a abordagem POLS. Foi realizado o teste de Breusch-Pagan para heterocedasticidade $(\mathrm{BG}=33,22$; p-valor $<0,000)$ e, com isso, rejeitou-se a hipótese de homogeneidade dos resíduos, indicando que o modelo deverá ser estimado, considerando erros-padrão robustos quanto à heterocedasticidade. Em seguida, verificou-se a estatística do fator de inflação da variância (FIV), sendo encontrado o valor médio de 2,56, variando entre 1,22 (DMEAUD) e 6,30 (SETOR 2). Portanto, considera-se que não há problemas de multicolinearidade nesse modelo. O teste RESET de Ramsey ( $\mathrm{F}=4,45$; p-valor $<0,0041)$ indicou que o modelo foi especificado corretamente. Foram realizados os testes de especificação de Chow $(F=0,82$; p-valor $<0,9114)$, Breusch-Pagan ( $\mathrm{BP}=0,00$; $\mathrm{p}$-valor $<1,000)$ e Hausman e, com isso, foram aceitas as hipóteses nulas. Esse resultado significa que a adequação do modelo com POLS foi aceita quando comparada com o modelo de EF, assim como quando comparada com o modelo de EA. Dessa forma, optou-se pelo modelo com abordagem de mínimos quadrados ordinários (POLS), uma vez que ele foi indicado como sendo o mais adequado.

Os resultados dos modelos com e sem tratamento dos outliers são apresentados na Tabela 9. Destarte, a variável VOLea, no modelo com outliers, apresenta uma relação positiva e significativa, já, no modelo sem outliers, a mesma variável não se mostrou significativa. Todavia, em relação às variáveis de controle, somente os setores da indústria têxtil e mobiliário apresentaram uma relação positiva e significativa; as demais variáveis não apresentaram relação significativa, em ambos os modelos.

Ao analisar a Tabela 9, observou se também uma relação positiva e não significativa entre a comparabilidade e o VOLena. Já a interação das variáveis 
Tabela 9 Modelo de Transferência de Informação Empresa de Auditoria

\begin{tabular}{|c|c|c|c|c|c|c|}
\hline \multirow{2}{*}{ Variável dependente: VOLena } & \multicolumn{3}{|c|}{ Com outliers } & \multicolumn{3}{|c|}{ Sem outliers } \\
\hline & $\begin{array}{l}\text { Pooled } \\
\text { (POLS) }\end{array}$ & EA & EF & $\begin{array}{l}\text { Pooled } \\
\text { (POLS) }\end{array}$ & EA & EF \\
\hline Intercepto & $-0,015$ & $-0,015$ & $-0,247$ & $-0,054$ & $-0,054$ & $-0,172$ \\
\hline VOLea & $0,089^{* *}$ & $0,089^{* *}$ & $0,101^{* *}$ & 0,051 & 0,051 & 0,055 \\
\hline COMPM & 0,000 & 0,000 & 0,000 & 0,000 & 0,000 & 0,000 \\
\hline COBA & 0,011 & 0,011 & 0,011 & $-0,006$ & $-0,006$ & $-0,004$ \\
\hline VOLea*COMPM & $0,008^{* * *}$ & $0,008^{* * *}$ & $0,009 * * *$ & $0,009^{* * *}$ & $0,009^{* * *}$ & $0,009^{* *}$ \\
\hline VOLea*COBA & $0,151^{* *}$ & $0,1515^{* *}$ & $0,128^{*}$ & $0,111^{* *}$ & $0,111^{* *}$ & $0,094^{*}$ \\
\hline $\mathrm{COMPM}^{*} \mathrm{COBA}$ & $-0,000$ & $-0,000$ & $-0,000$ & $-0,000$ & $-0,000$ & 0,000 \\
\hline VOLea*COMPM*COBA & $-0,009^{* *}$ & $-0,009^{* *}$ & $-0,010^{* *}$ & $-0,010^{* * *}$ & $-0,010^{* * *}$ & $-0,010^{* *}$ \\
\hline ALAV & 0,023 & $0,023^{*}$ & 0,047 & 0,008 & 0,008 & 0,003 \\
\hline TAM & $-0,002$ & $-0,002$ & 0,007 & $-0,004$ & $-0,004$ & $-0,002$ \\
\hline MTBDIF & $-0,002$ & $-0,002$ & $-0,001$ & $-0,001$ & $-0,001$ & 0,000 \\
\hline END & 0,019 & 0,019 & 0,052 & 0,028 & 0,028 & $0,076^{*}$ \\
\hline RLAG & 0,001 & 0,001 & 0,018 & 0,022 & 0,022 & $0,039^{*}$ \\
\hline DPREJ & 0,015 & 0,015 & 0,010 & 0,009 & 0,009 & 0,003 \\
\hline 2.Serviços utilidade pública & $-0,006$ & $-0,006$ & & 0,007 & 0,007 & \\
\hline 3.Construção de edifícios & 0,007 & 0,007 & & $-0,012$ & $-0,012$ & \\
\hline 4. Indústria de alimentos & $-0,006$ & $-0,006$ & & 0,003 & 0,003 & \\
\hline 5. Indústria têxtil & $0,061^{* *}$ & $0,061^{* * *}$ & & $0,051^{* *}$ & $0,051^{* *}$ & \\
\hline 6. Indústria química & 0,003 & 0,003 & & 0,003 & 0,003 & \\
\hline 7.Indústria de metal primário & 0,018 & 0,018 & & 0,024 & 0,024 & \\
\hline 8.Indústria de produtos de metal & $-0,015$ & $-0,015$ & & $-0,021$ & $-0,021$ & \\
\hline 9. Indústria de máquina & $-0,002$ & $-0,002$ & & 0,000 & 0,000 & \\
\hline $\begin{array}{l}\text { 10.Fábrica de equipamentos de } \\
\text { Transporte }\end{array}$ & 0,024 & $0,024^{*}$ & & 0,004 & 0,004 & \\
\hline 11. Telecomunicações & 0,002 & 0,002 & & 0,008 & 0,008 & \\
\hline 12. Mobiliário & $0,050^{* *}$ & $0,050^{* * *}$ & & $0,039^{*}$ & $0,039^{*}$ & \\
\hline $\begin{array}{l}\text { OBS } \\
R^{2} \\
R^{2} \text { ajustado } \\
\text { Est. F }\end{array}$ & $\begin{array}{c}854 \\
0,093 \\
0,334 \\
2.764\end{array}$ & $\begin{array}{c}854 \\
0,093\end{array}$ & $\begin{array}{c}854 \\
0,062 \\
0,062 \\
2.482\end{array}$ & $\begin{array}{c}810 \\
0,080 \\
0,295 \\
2,826\end{array}$ & $\begin{array}{l}810 \\
0,08\end{array}$ & $\begin{array}{c}810 \\
0,041 \\
0,038 \\
2.248\end{array}$ \\
\hline
\end{tabular}

Nota: ${ }^{*} p<0.1 ;{ }^{* *} p<0.05 ;{ }^{* * *} p<0.01$

VOLea $\times$ COMPM e VOLea $\times$ DMEAUD apresentou uma relação positiva e significativa, enquanto a variável das variáveis VOLea $\times$ COMPM $\times$ DMEAUD evidenciou uma relação negativa, mas significativa.
Para essas variáveis, os resultados não divergiram substancialmente com a presença de outliers.

$\mathrm{O}$ intuito do teste da hipótese $\mathrm{H}_{2}$ era verificar se o aumento do volume anormal de negociação, em torno dos anúncios de resultados, experimentado por 
uma empresa que compartilha a mesma empresa de auditoria com seus pares, no setor econômico, está associado, positivamente, ao aumento da comparabilidade de seus relatórios financeiros. As evidências sugerem que, de maneira geral, a hipótese $\mathrm{H}_{2}$ não pode ser confirmada em sua totalidade, visto que as variáveis COMPM e DMEAUD sozinhas e a interação COMPM×DMEAUD não apresentaram efeito significativo no VOLena. Todavia, a interação das variáveis VOLea com a COMPM, VOLea com DMEAUD, e VOLea $\times$ COMPM $\times$ DMEAUD apresentou-se significativa para ambos os modelos, apesar de a interação ser negativa em ambos os modelos.

\section{CONSIDERAÇÕES FINAIS}

O objetivo geral desta pesquisa foi avaliar a influência da comparabilidade dos relatórios financeiros na transferência de informação, considerando os efeitos das externalidades em torno dos anúncios de resultados das empresas. O pressuposto da pesquisa firmava-se em que os anúncios de resultados das companhias geram externalidades das informações, capaz de produzir reações no comportamento dos investidores, que podem estar associadas à comparabilidade e a transferência de informações. Assim, a comparabilidade dos relatórios financeiros poderia funcionar como um previsor de monitoramento dos padrões de informações divulgadas, em função da capacidade de minimizar os efeitos negativos das externalidades dessas informações.

O estudo revelou uma interação significativa e negativa entre as variáveis: volume anormal de negociação, comparabilidade, e cobertura de analistas, sugerindo que o efeito da comparabilidade sobre a transferência de informação não depende totalmente da quantidade de analistas que acompanham as empresas. Esse resultado, entretanto, reforça os achados de Henry et al. (2020), de que a mudança na comparabilidade de duas empresas afetará os analistas, assim como, na percepção desses analistas, afetará as informações transferidas.

Identificou-se também, que as empresas que anunciam primeiro seus resultados apresentaram uma associação significativa entre o volume anormal de negociação e a cobertura de analistas. Tal resultado confirma os achados de Hilary e Shen (2013), quanto ao entendimento do analista em relação à empresa anunciadora, e que esse entendimento afeta não só a eficiência da transferência de informações dentro do setor, como a capacidade do analista de interpretar as informações divulgadas. Além disso, os resultados amparam a visão defendida por Byard et al. (2018), de que níveis anormais de cobertura de analistas transmitem informações mais úteis para as empresas e podem ser um forte preditor de desempenho futuro das companhias.

Quanto à interação das variáveis: volume anormal de negociação e comparabilidade e volume anormal de negociação com a mesma empresa de auditoria, os resultados mostraram uma relação positiva e significativa. Tais achados sugerem que a comparabilidade dos relatórios financeiros está associada à reação do mercado quanto ao volume anormal de negociação, e que, quando as empresas do setor são auditadas pela mesma firma de auditoria, a comparabilidade dessas empresas tende a ser maior, em função da similaridade no trabalho e das normas internas das empresas de auditoria. Essa perspectiva corrobora os resultados de Francis, Pinnuck e Watanabe (2014) e Franco, Hou e Ma (2019).

Outra evidência do estudo relaciona-se ao tempo de divulgação das empresas e sua capacidade de produzir externalidades das informações entre as empresas, no mercado de capitais, em função de transferirem informações entre as companhias que anunciam primeiro e as empresas que anunciam posteriormente. Nesse sentido, o estudo mostrou que esses efeitos econômicos, gerados como externalidades da divulgação, são ainda maiores à medida que as empresas são líderes de mercado em seu setor econômico, e que há uma tendência de imitação nas divulgações entre as companhias que anunciam primeiro e as que anunciam posteriormente.

Por fim, destaca-se como evidência da pesquisa a utilização do volume anormal de negociação como medida não assinalada, capaz de produzir insights a respeito da redução da assimetria de informação no mercado. Essa medida captura as transferências de informações em torno do conteúdo dos anúncios no mercado de capitais, mesmo com a divulgação simultânea de outros relatórios financeiros. Assim, o efeito provocado na redução do conteúdo infor- 
macional das demais empresas do setor tende a ser menor, uma vez que as reações do mercado, quando medidas por meio dos retornos das ações, são diferentes quando comparadas ao volume de negociação. Esse efeito diferenciado ajuda a dissipar os efeitos da seleção adversa, à medida que maior quantidade de informação divulgada sobre a empresa pode gerar menor reação para o volume de negociação.

Entende-se que esta pesquisa apresenta como principal limitação a exclusão dos setores econômicos com menos de cinco empresas, para minimizar os efeitos cruzados da divulgação e os efeitos de contágio. Nesse sentido, não fizeram parte do estudo os seguintes setores: Mineração; Construção pesada e engenharia civil; Fábrica de produtos de couro; Fábrica produtos de madeira; Fábrica de papel; Indústria de produtos de petróleo e carvão; Indústria de produtos minerais não metálicos; Indústria de computadores e produtos eletrônicos; Fábrica de equipamentos e componentes elétricos; Fábricas diversas; Comércio atacadista de bens duráveis; Loja de saúde e cuidados pessoais; Lojas de vestuário e acessórios; Lojas de departamentos; Atividades de suporte para transporte; Serviços profissionais, científicos e técnicos; Serviços de cuidados de saúde e ambulatoriais.

\section{REFERÊNCIAS}

ALVES, P.; POPE, P.F.; YOUNG, S. Cross-border information tranfers: evidence from profit warnings issued by europen firms. Accounting and Business Research, v. 39, n. 5, p. 449-474, 2011. https://doi.or g/10.1080/00014788.2009.9663378

BAGINSKI, S. P. Intraindustry Information Transfer Associated with Management Forecast of Earnings. Journal of Accounting Research, v. 25, n. 2, p. 196216, 1987. https://doi.org/10.2307/2491015

BAMBER, L.; BARRON, O.; STEVENS, D. Trading volume around earnings announcements and other financial reports: Theory, research design, empirical evidence, and directions for future research. Contemporary Accounting Research, v. 28, p. 431-471, 2011. https://doi. org/10.1111/j.1911-3846.2010.01061.x
BYARD, D.; DARROUGH, M.; SUH, J.; TIAN, Y. Finding diamonds in the rough: Anausts'selective following of loss-reporting firms. Journal of Business Finance \& Accounting, v. 45, n. 1-2, p. 140-165, 2018. https://doi.org/10.1111/jbfa.12269

BYARD, D.; MASHRUWALA, S.; SUH, J. Does the 20-F reconcoliation affect investors' perception of comparability between foreigh private issuers (FPIs) and U. S. firms? Accounting Horizons, v. 31, n. 2, p. 1-23, 2017. https://doi.org/10.2308/acch-51635

CHEN, C.; YOUNG, D.; ZHUANG, Z. Externalities of Mandatory IFRS Adoption: Evidence from CrossBorder Spillover Effects of Financial Information on Investment Efficiency. The Accounting Review, v. 88 , n. 3, p. $881-914,2013$. https://doi.org/10.2308/ accr-50384

FRANCO, G.; KOTHARI, S.; VERDI, R. S. The benefits of financial statement comparability. Journal of Accounting Research, v. 49, n. 4, p. 895-931, 2011. https://doi.org/10.1111/j.1475-679X.2011.00415.x

FOND, M.; HU, X.; HUNG, M.; LI, S. The impact of mandatory IFRS adoption on foreign mutual fund ownership: The role of comparability. Journal of Accounting and Economics, v. 51, n. 3, p. 240-258, 2011. https://doi.org/10.1016/j.jacceco.2011.02.001

FRANCO, G.; HOU, Y.; MA, M. Do firm mimic their neighbors "accounting"? Industry peer headquarters co-location and financial statement comparability. SSRN, 2019. Disponível em: https://ssrn.com/abstract=3310219. Acesso em: 09 mar. 2021. https://doi. org/10.2139/ssrn.3310219

FANG; V. W.; MAFFETT, M.; ZHANG, B. Foreign Institutional Ownership and the Global Convergence of Financial Reporting Practices. Journal of Accounting Research, v. 53, n. 3, p. 593-631, 2015. https://doi.org/10.1111/1475-679X.12076

FÁVERO, L. P.; BELFIORE, P.; TAKAMATSU, R. T.; SUZART, J. Métodos Quantitativos com Stata: Procedimentos, Rotinas e Análise de Resultados. 1. ed. Rio de Janeiro: Elsevier. 2014. 
FERNANDES, S. M. Os efeitos do disclosure ambiental negativo involuntário: um estudo de evento nas companhias brasileiras com alto índice de poluição. Revista de Contabilidade e Organizações, v. 7, n. 17, p. 56-68, 2013. https://doi.org/10.11606/rco. v7i17.56668

FRANCIS, J.; PINNUCK, M.; WATANABE, O. Auditor style and financial statement comparability. The Accounting Review, v. 89, n. 2, p. 605-633, 2014. https://doi.org/10.2308/accr-50642

FREEMAN, R.; TSE, S. An earnings prediction approach to examining intercompany information transfers. Journal of Accounting and Economics, v. 15, p. 509-523, 1992. https://doi. org/10.1016/0165-4101(92)90004-L

FIRTH, M. The transmission of corporate financial information across borders and equity market linkages. Review of Accounting Studies, v. 1, p. 309-227, 1996. https://doi.org/10.1007/BF00570835

FOLSTER, A. Impacto da Evidenciação de Guidance: um Estudo de Evento no Mercado Brasileiro. Revista de Contabilidade da UFBA, v. 12, n. 2, p. 183-200, 2018. http://dx.doi.org/10.9771/rc-ufba.v12i2.21465

FOSTER, G. Intra-industry information transfers associated with earnings releases. Journal of Accounting and Economics, v. 3, p. 201-232, 1981. https://doi.org/10.1016/0165-4101(81)90003-3

GROSS, C.; PEROTTI, P. Output-based measurement of accounting comparability: a survey of empirical proxies. Journal of Accounting Literature, v. 39, p. 1-22, dez. 2017. https://doi.org/10.1016/j. acclit.2017.09.002

GUJARATI, D. N.; PORTER, D. C. Econometria básica. Porto Alegre: AMGH Editora Ltda. 2011.

HABIB, A.; HASAN, M. M.; AL-HADI, A. Financial statement comparability and corporate cash holdings. Journal of Contemporary Accounting \& Economics, v. 13, n. 3, p. 304-321, 2017. https://doi.org/10.1016/j. jcae.2017.10.001
HAN, J. C. Y.; WILD, J. J. Unexpected Earnings and Intraindustry Information Transfers: Further Evidence. Journal Accounting Research, v. 28, n. 1, p. 211-219, 1990. https://doi.org/10.2307/2491225

HENRY, E.; LIU, F. C.; YANG, S. Y.; ZHU, X. Does Financial Statement Structural Comparability Affect Analysts' Forecasts? SSRN, 2020. Disponível em: https://ssrn.com/abstract=3133324. Acesso em 09 mar. 2021. http://dx.doi.org/10.2139/ssrn.3133324

HILARY, G.; SHEN, R. The role of analysts in intra-industry information transfer. The Accounting Review, v. 88, n. 4, p. 1265-1287, 2013. https://doi. org/10.2308/accr-50437

YIP, R. W.; YOUNG, D. Does Mandatory IFRS Adoption Improve Information Comparability? The Accounting Review, v. 87, n. 5, p. 1767-1789, 2012. https://doi.org/10.2308/accr-50192

YOUNG, S.; ZENG, Y. Accounting comparability and the accuracy of peer-based valuation models. The Accounting Review, v. 90, n. 6, p. 2571-2601, 2015. https://doi.org/10.2308/accr-51053

KIM, J.; LI, L. L. LU. Y.; YU, Y. Financial statement comparability and expected crash risk. Journal of Accounting and Economics, v. 61, n. 2-3, p. 294-312, 2016. https://doi.org/10.1016/j.jacceco.2015.12.003

KIM, O.; VERRECCHIA, R. E. Trading volume and price reactions to public announcements. Journal of Accounting Research, v. 29, n. 2, p. 302-321, 1991. https://doi.org/10.2307/2491051

LI, Q.; LUMENG, W. Financial statement comparability and corporate tax avoidance. China Journal of Accounting Studies, v. 6, n. 4, p. 448-473, 2018. https://doi.org/10.1080/21697213.2019.1612187

MACKINLAY, A. C. Association Event Studies in Economics and Finance. Journal of Economic Literature, v 35, n. 1, p. 13-39, 1997. http://www.jstor. org/stable/2729691 
MELLACI, M.; PETROKAS, L. A.; FAMA, R. Análise do impacto do investimento de patrocínio esportivo pelo Banco Panamericano: estudo de evento. Brazilian Business Review, v. 9, p. 106-124, 2012. http://dx.doi.org/10.15728/bbrconf.2012.4

OLIVEIRA, R, X.; GONÇALVES, R. S.; MEDEIROS, O. R.; FERNANDES, B. V. R. Cobertura de analistas de mercado e social disclosure: evidências em empresas brasileiras abertas. Advances in Scientific and Applied Accounting, v. 11, n. 1, p. 24-46, 2018. http:// dx.doi.org/10.14392/asaa.2018110102

PANDIT, S.; WASLEY, C. E.; ZACH, T. Information Externalities along the Supply Chain: The Economic Determinants of Suppliers' Stock Price Reaction to Their Customers' Earnings Announcements. Contemporary Accounting Research, v. 28, n. 4, p. 1304-1343, 2011. https://doi. org/10.1111/j.1911-3846.2011.01092.x

REINA, D. R. M.; CARVALHO, L. N. G.; REINA, D.; LEMES, S. Comparabilidade dos relatórios financeiros e informatividade dos preços das ações no Brasil. Revista Contemporânea de Contabilidade. v. 16, n. 39, p. 177-198, 2019. https:// doi.org/10.5007/2175-8069.2019v16n39p177

REINA, D.; SILVA, W. A. M.; LEMES, S.; REINA, D. R. M. Efeito da Comparabilidade dos Relatórios Financeiros em Torno do Anúncio dos Lucros. XX USP International Conference in Accounting, São Paulo, 2020.

RIBEIRO, A. M.; CARMO, C. H. S.; FÁVERO, L. P. L.; CARVALHO, L. N. Poder discricionário do gestor e comparabilidade dos relatórios financeiros: Uma análise do processo de transição regulatória da contabilidade brasileira. Revista Contabilidade e Finanças, v. 27, n. 70, p. 12-28, 2016. https://doi. org/10.1590/1808-057x201601900
ROYCHOWDHURY, S.; SHROFF, N.; VERDI, R. $S$. The effects of financial reporting and disclosure on corporate investment: A review. SSRN, 2019. Disponível em: https://ssrn.com/abstract=3429337. Acesso em: 09 mar. 2021. https://doi.org/10.2139/ ssrn.3364582

SILVA, R. L. Adoção completa das IFRS no Brasil: qualidade das demonstrações contábeis e o custo de capital próprio. Tese (Doutorado). Faculdade de Economia, Administração e Contabilidade. Universidade de São Paulo. São Paulo. 2013.

THOMAS, J.; ZHANG, F. Overreaction to intra-industry information transfers? Journal of Accounting Research, v. 46, n. 4, p. 909-940, 2008. https://doi. org/10.1111/j.1475-679X.2008.00294.x

WANG, C. Accounting Standars Harmonization and Financial Statement Comparability: Evidence from Transnational Information Transfer. Journal of Accounting Research, v. 52, n. 4, p. 955-992, 2014. https://doi.org/10.1111/1475-679X.12055

WEICHAO, L.; DAOGUANG, Y.; SIYI, L. Accounting information comparability, demand differences and cross-firm information transfer. China Journal of Accounting Studies, v. 6, n. 3, p. 321-361, 2018. https:// doi.org/10.1080/21697213.2018.1567113 